\title{
Control-Enhancing Mechanisms in Italian Companies
}

\author{
Carmelo Intrisano \\ University of Cassino, Cassino, Italy
}

\begin{abstract}
Dual class systems, shareholder agreements and pyramid structures are legal devices whereby shareholders are able to separate voting rights from cash flow rights. These practices are used to strengthen the decision-making power of a small number of controlling shareholders to the potential detriment of many minority shareholders, whose vote becomes ineffective. In this way, controlling shareholders have the possibility of influencing or dictating corporate governance with the higher majority of voting rights that they obtain. These mechanisms are very different from each other and this paper demonstrates that regulatory changes, regarding the protection of shareholders which occurred in the Italian market from 1999 to 2007, have produced different effects on the mechanisms of separation between ownership and control, especially with regard to their diffusion among companies. In the same way, this work provides evidence that these mechanisms have the fact that they are more popular in larger companies in common, due to their higher needs of equity associated to the acquisition of control. Thus, the idea of this study is to analyze and measure the implementation of dual class systems, shareholder agreements and pyramid structures in Italian listed companies between 1999 and 2007.

Keywords: dual class, shareholder agreements, pyramidal structure, voting rights, cash flow rights, controlling shareholder
\end{abstract}

\section{Introduction}

In recent years, the dichotomy is not so much a question of the relationship between shareholders on one hand and stakeholders on the other, as much as it concerns the relationship between ownership on the whole and the shareholder that ends up taking full control of the company by intensifying the separation between voting rights and cash flow rights. From some points of view this can be understood as a clear demonstration of how rapidly modern capitalism has been deteriorating over the past few years with shareholders that do not link their controlling position to invested capital, but to their ability to exploit the capital of other shareholders as much as possible, limiting the financial investment associated to control.

It follows that the controlling shareholders recur to the different control enhancing mechanisms as devices that allow the violation of proportionality between control and ownership.

Obviously, this choice does not have the same intensity in the countries, but instead assumes different

\footnotetext{
Carmelo Intrisano, Professor of Corporate Finance, Department of Enterprise, Environment and Management, University of Cassino.

Correspondence concerning this article should be addressed to Carmelo Intrisano, Sant'Angelo Road, Cassino, Italy. E-mail: c.intrisano@eco.unicas.it.
} 
dimensions. In this way a regulatory environment characterized by a low level of shareholder protection can encourage the companies to implement such policies, given that, differences in legal protection of investors can help to explain as to why the financing policy and the ownership structure differ among countries, as amply demonstrated by La Porta, Lopez-de-Silanes, Shleifer, and Vishny (1998). These same characteristics of the market on the whole however can seem to have some relevance as stated in a EU report on the proportionality between ownership and control in European listed companies. According to this report, the gap between the availability of Control Enhancing Mechanisms (CEMs) and their actual use by companies tends to indicate that the market's normal practice and expectations play an important role in the selection of these instruments. Even a country's specific legal limitations concerning the use of single separation mechanisms can influence the implementation by companies.

Therefore, with only a complete vision of all potential elements able to influence the diffusion of CEMs between companies can we explain as to why, for example, countries such as France, Sweden, Italy and Spain have a higher concentration of CEMs. In fact, whilst the reason for this in France, Italy and Spain is probably explained by the low level of shareholders protection offered by French legal origin countries, the reason for the high level in Scandinavian countries however is of a different nature, given that they have an intermediate level of investor protection.

With particular regards to Italy, the legislative changes concerning financial markets, since the Draghi Reform Act (Testo Unico sulla Finanza) of 1998, have probably influenced the implementation of CEMs, that while maintaining at particularly intense levels with respect to the rest of Europe, it has seen a progressive downturn over the years.

The regulations included in the Reform Act, aimed at guaranteeing transparency within the markets and company structures, as well as to regulate the right to disinvest a fair (as it is the case in tender offers) and to ensure the improvement of the right to self-protection for qualified minorities ${ }^{1}$. Regarding CEMs more specifically, the act introduced organic legislation of shareholders agreements, which not only definitively ratifies their legitimacy and their validity but also elevates their transparency ${ }^{2}$.

Other contributions towards the protection of shareholders were brought about by the introduction of the Listed Companies’ Self-discipline Code (Codice di Autodisciplina delle Società Quotate) in $1999^{3}$, from the

\footnotetext{
${ }^{1}$ For example, article 120 of the Draghi Reform Act establishes the obligation of communication to the participating company and to Consob, for all current shareholders of a holding superior to $2 \%$. Further communications are necessary when reaching $5 \%$, $7.5 \%, 10 \%$ and successive multiples of 5; as well as when the percentage falls below these percentages. Also article 106 of the Draghi Reform Act determines that whoever acquires with cash or cash equivalents, stakes either directly or indirectly more than $30 \%$ of common stock of a listed company is required to promote a tender offer of the common stock that is still in circulation at a minimum price equal to the arithmetic mean between the weighted average price in the last 12 months and the highest price paid within the same period by the tenderer for acquisitions outside the Stock Exchange for common stock. Moreover, article 125 of the Draghi Reform Act provides for the convocation of a shareholder's meeting on request by the minority, article 128 establishes the notification to the Board of Directors, article 129 sanctions social action of responsibility promoted by a qualified minority.

2 Article 122 of the Draghi Reform Act, establishes the obligation of communication to Consob within five days of the stipulation, obligation of the publication in the daily press within 10 days of its stipulation as well as the obligation to deposit with the company register within 15 days of the stipulation, while article 123 defines a three-year duration of agreements, if stipulated as an fixed-term contract and provides for a party to recede from open-ended agreements with notice, as well as the possibility of adhering to a tender offer and recede without notice from the agreement.

${ }^{3}$ With the voluntary adhesion to the Self-Discipline Code, listed companies make transparent the principles adopted regarding corporate governance with reference to the functions and the relations between the managing bodies and control of the company to shareholders and to the market.
} 
reform of companies law in $2003^{4}$ and from the Savings Law in $2005^{5}$. These norms introduced new measures able to influence the protection of minorities at quite a significant level.

The improvements for the rights of non-controlling shareholders achieved are reflected with different intensity on the degree of implementation for the dual class system, shareholder agreements and pyramid structures, especially regarding the effects that they are able to generate on the proportionality between ownership and control.

In particular, savings shares were legally introduced in the Italian system in the 1974, being shares that carry no voting rights and have priority in the payment of dividends and upon liquidation. There is internal mechanism whereby the majority shareholder reaches and/or strengthens control whilst limiting its financial investment.

The pyramid chain however, is an external separation mechanism because it requires the creation of more companies. As a consequence the effects produced (which are more consistent than those produced by the dual class mechanism) are distributed at different levels of each company that is part of the chain rather than being concentrated on the company itself. In fact, due to the cascade effect of the chain, the top of the pyramid is able to assure a majority voting rights in each level, usually with a contained financial investment with respect to the amount of control gained.

Finally, unlike dual class shares and pyramid structures, shareholder agreements are instruments with which the control is shared between multiple shareholders rather than being concentrated on one shareholder alone. As a result, the effect that these agreements generate can be interpreted as a strengthening of the intrinsic value or the utility of the voting right held by each single adherent usually represented by the number of members of the Board of Directors that each participant is able to appoint.

With all these in mind, this article is divided into five sections. The first section focuses on relevant literature regarding the topic, the second describes the methods used while the other sections develop the research through the analysis and the estimate of the degree of separation between ownership and control during the years studied.

\section{Literature Review}

Since the relationship between ownership and control was first touched upon by Berle and Means (1932) with reference to the American corporate system, literature on this topic has increased greatly. Some authors have focused on elements that are capable of influencing the ownership structure (Demsetz \& Lehn, 1985) while others have investigated the differences in ownership structures among countries and the possible relationships with legislation that protects investors (La Porta, Lopez-de-Silanes, \& Shleifer, 1999) and still others have focused on the relationship between ownership and control.

\footnotetext{
${ }^{4}$ With the reform of companies law, along with other measures, duties of the directors and auditors were reinforced, the figure responsible for accounting controls was introduced, the auditor; stock company obligations concerning information were strengthened; the different models of corporation were differentiated, with the introduction of monistic, dualistic and traditional systems; responsibility of social action of minorities was regulated regarding the directors, the discipline of company groups was revised, and the discipline regarding means of financing different from bank debts were redefined.

5 The Savings Law (No. 262 of 2005) had the main objective of the protection of savers and the revising of the discipline of financial markets, which caused, amongst other things, changes regarding corporate governance with reference to the requisites for the appointment of directors, the composition and powers of the board of statutory auditors, concerning actions of responsibility against directors; refers to Consob the discipline for the solicitation to vote for companies with high capitalization and diffused share-base; introduces the discipline for Italian companies that control foreign companies based in countries that do not guarantee transparency; regulates the conflict of interests between banks and companies; introduces transparency rules for companies that deliberate stock option plans.
} 
With reference to this topic, many researchers have studied the CEMs, but rarely analyzing them all together as alternative options to separate voting rights from cash flow rights.

Therefore about dual class model, many authors such as Grossman and Hart (1988) studied the topic in order to identify the optimal ownership structure between one share-one vote and the dual class system. The two authors demonstrate that in certain hypotheses and with reference to listed companies, the one share-one vote model is the optimal structure for companies that intend to maximise market price that investors are willing to pay. According to Burkart and Lee (2008), however, one share-one vote is suboptimal because while it ensures an efficient outcome in bidding contests, the other is unable to influence the free-riding, unlike the dual class model.

Other scholars such as Zingales (1994) studied the dual class mechanism to measure the private benefits of control within companies listed in the Milan Stock Exchange, based upon the difference in stock prices between voting and non-voting shares.

With reference to shareholder agreements, many authors have studied the matter in order to demonstrate the superior efficiency of coalitions compared to single members, as the command coalition, bringing together the cash flow of shareholders participating in the coalition, leads to increased internalization of the consequences produced by its actual decisions (Bennedsen \& Wolfenzon, 2000).

Other positive aspects of commanding coalitions have been detected by Laeven and Levine (2008), who have recognised the positive effect upon the company's value from a greater distribution of voting rights and dividend rights between multiple large owners when studying a sample of companies in 13 European countries. The same acknowledgement was found by Faccio, Lang, and Young (2001) who argue the positive role played by multiple shareholders, demonstrating that where more present there is a reduction in the expropriation of small shareholders which is shown by higher dividend rates. Gomes and Novaes (2005) also demonstrate the positive effects of controlling coalitions as they allow the prevention of, or at least limit, the decisions that only produce benefits for the controlling group and damage minority shareholders. Moreover, Chemla, Habibe, and Ljungqvist (2007) have focused on the covenants and provided an economic explanation for the use of these clauses in shareholders' agreements.

Referring to Italy, the investigation by Gianfrate (2007) demonstrates particularly interesting results on the consequences produced by syndicate agreements in terms of disproportionality between board rights on one side and dividend rights on the other. He estimates that on average a voting agreement with a syndicated share $52 \%$ of cash flow rights is able to exercise up to $87 \%$ of rights to elect a company board of directors.

Likewise, regarding the pyramid model some authors have focused on their functions. As it is the case with other groups, the pyramid group can replace capital markets in the development process of countries (Khanna \& Palepu, 1997). This is proved by the fact that pyramidal groups are more common in countries with low investor protection and low development of capital markets (La Porta, Lopez-de-Silanes, Shleifer, \& Vishny, 1997; Faccio \& Lang, 2002). More specifically the groups can ease the raising of capital by replacing external resources with those originating from inside the group. The proof of this lies in higher debt within the Italian pyramid groups present in holdings rather than controlled companies, where it is the parent company that tends to concentrate on financial procurement for the different pyramid levels (Piga, 2002; Bianco \& Nicodano, 2006). Riyanto and Toolsema (2008) have instead connected the existence of pyramid groups to tunnelling and propping, which entails the bidirectional transfer of resources from the bottom to the top and from the top to the bottom of 
the chain. In particular, the transfer of resources from the controller sometimes makes it necessary to guarantee the salvage of group member companies who would otherwise be destined for bankruptcy by injecting capital. In fact, in these situations it is difficult for the controller not to intervene considering the cost in reputation that it would expose itself to with the controlled company's default (Gopalan, Nanda, \& Seru, 2007). Whereas the transfer of resources from the lower levels of the pyramid chain is substantially referred to the possibility of diverting earnings of the subsidiaries of the holding (Johnson, La Porta, Lopez-de, Silanes, \& Shleifer, 2000; Bertrand, Mehta, \& Mullainathan, 2002).

Other authors have studied pyramid structures in order to estimate the effects on performance. These have concluded that the member companies of pyramid groups generally have a lower Tobin's Q compared to others due to the fact that groups discourage the search for actions optimizing the performance (Claessens, Fan, \& Lang, 2006).

On the contrary, Almeida and Wolfenzon (2006) who begin from the assumption that pyramids increase the separation between cash flow rights and voting rights, stated that the pyramidal structure is the means by which a family uses a company that is already controlled in order to establish a new company.

The chains of control were also objects of investigation in numerous empirical evidence, some of which regarding emerging economies such as the example given by Gangopadhyay, Lensink, and Van der Molen (2003) on Indian groups, while others in more advanced countries with research conducted on American companies by Lamont (1997) and by Shin and Stultz (1998).

In Italy, the investigation by Bianchi, Bianco, and Enriques (2001) shows that in 1996 more than 50\% of Italian companies belong to a pyramid group, with a separation between ownership and control equal to an average value of 2.4 of controlled capital per unit of capital held.

A comparative analysis between pyramid structures and shareholder agreements within Italian companies is included in the study of Volpin (2002), who examines the ownership structure in order to analyse the sensitivity of director turnover on the performance and on the Q-ratio. The article suggests that the sensitivity of the turnover is larger and the Q-ratio is significantly higher when a shareholder agreement controls the company, whilst the executive turnover is not significantly influenced by the company's organisational structure and the Q-ratio is lower in companies near the top of the pyramid compared with those who are not part of a group.

This brief review shows that in the literature on this topic, there are few contributions on the CEMs conceived as an overview on different alternative to separate voting rights from cash flow rights and are equally few empirical evidence on the prevalence and evolutionary dynamics in Italy.

Likewise, even though the study commissioned by the European Union in 2006 on the proportionality between ownership and control in listed European companies contains an overall vision of the subject for the whole of Europe by measuring the differences in the intensity between European countries, it does not provide data on the evolution of the phenomenon being referred to a single year.

Hence the idea of this study is to analyse and demonstrate, the differences in the CEMs measuring the intensity and highlighting trends in Italy, from 1999 to 2007, considering the changes in the protection of shareholders.

\section{Survey Methodology}

The analysis of the three methods to separate voting rights and ownership rights was carried out on all companies listed in the Milan Stock Exchange from 1999 to 2007. As such the investigation is not based on 
samples but refers to the entire population of listed companies in the Italian market.

As the beginning of the observation period 1999 was chosen because it is the year immediately after the adoption of the Legislative Decree No. 58 of 24th February 1998 (D.Lgs. No. 58 24/02/1998) which deeply revised government regulations for listed companies, and introduced changes to the discipline on takeover bids and appropriate constraints of information and transparency in order to improve the protection of minority shareholders.

The period was extended until 2007 to include the full effects of other acts such as the Corporate Law Reform Act of 2003 and Law No. 262 of 28th December 2005 introducing new rules for the protection of savings and the regulation of financial markets.

Data on ownership structures was gathered through the analysis of Consob archives and publications.

In particular, for the qualification of the controlling company, this paper verified if the number of shares held allows the leading shareholder to safe-guard the company's decision-making process, considering the provisions established by the Italian Civil Code with respect to shareholders' resolutions of companies listed on the market ${ }^{6}$.

Given that a quorum for corporate meetings must only be obtained for the first ordinary meeting, control can be established in future meetings through the majority of votes from the shareholders present at the same. This is not true in the case of an extraordinary general meeting, given that a quorum for corporate meetings must be obtained, in accordance to relative provisions, for all meetings, even after the first. In this case, the shareholder that intends to exercise control must take protective measures to make sure other shareholders do not work against him, taking advantage of quora for corporate meetings ${ }^{7}$. Based on these hypotheses, in the present research, three distinct degrees of control can be identified:

- First degree of control: The shareholder, or group of shareholders, holding the absolute majority of votes takes decisions both in the ordinary meeting and in the extraordinary meeting;

- Second degree of control: The leading shareholder, or group of shareholders, holds a percentage that allows them to take decisions in future meetings, both in ordinary meetings and in extraordinary meetings, regardless of whether or not the absolute majority of votes is obtained;

- Third degree of control: The leading shareholder, or group of shareholders, is only able to take decisions in future ordinary meetings, but not in extraordinary meetings.

The first grade obviously denotes more of a burden than the second grade and even more so than the third in terms of effectiveness of control. In fact in the first the controller has the ability of deliberating in the first convocation in ordinary meetings and in extraordinary meetings. In the second this capacity is limited to the

\footnotetext{
${ }^{6}$ Under the terms of the third paragraph of art. 2369 Civil Code in the second calling the ordinary meeting deliberates on the objects that should have been dealt with in the first, irrespective of the capital represented by shareholders attending, and the extraordinary general meeting is duly constituted with the participation of over one third of the capital and acts with the affirmative vote of at least two-thirds of the shares represented at the meeting. In particular, according to the seventh paragraph of that article, for the companies using the capital market an extraordinary general meeting is constituted, in subsequent calling to the second, with the presence of shareholders representing at least a fifth of the share capital, except when a higher share capital is required by the corporate statute.

7 The awareness that the majority of votes established by the quorum for making resolutions in the extraordinary meetings will not be obtained can lead shareholders to choose not to participate in successive meetings, causing the company to come to a standstill and compromising control on behalf of the shareholders.
} 
second convocation for both types of assembly, and lastly in the third only in ordinary meetings.

Nevertheless, while assessment of the first degree of control only requires majority rule, assessment of the second and third depends on the percentage of capital that may be used for voting, of which only shareholders with more than $2 \%$ may be considered. In fact it is probable that shareholders owning less than $2 \%$ of share capital rarely participate in companies' meetings, conscious of the fact their limited amount of shares does not consent any decision-making power in the meetings.

For this reason, this paper exclusively considers large shareholdings, as established by Consob, in terms of capital which may be used for voting in companies' meetings and which is thus directly related to the quora required for shareholders' meetings and resolutions in meetings following the first.

In particular, regarding the second and third degrees of control, it can be seen that:

- The first degree of control is subject to simple ownership of 50 per cent of the voting rights;

- The second degree of control is conditional on the highest of the two: 66.67\% (2/3 majority) of holdings (hypothetically correspondent to the capital which really may be used for voting in meetings) or $20 \%$ of share capital, considering that the first degree also allows for rulings in ordinary and extraordinary meetings;

- The third degree of control is conditional on merely obtaining the majority of votes of those who are present, which, however, is less than the greater value between $66.67 \%$ of holdings and $20 \%$ of share capital.

Therefore, on this basis, the dual-class companies were identified, first of all, considering among companies listed on the MSE those with limited voting shares, and then reconstructing for each company, the percentage of voting rights held by the majority shareholder and the percentage of non-voting shares on the total share capital.

In order to estimate the extent to which shareholder agreements are diffused between companies listed on the Italian Stock Exchange, agreements in force between 1999 and 2007 were analyzed, reconstructing the duration, number and kind of members, eventual variations in dates of commencement and dates of expiry, renewals as well as the percentage of share capital subject to a shareholders agreement and shares held by the parties involved.

Pyramidal groups were identified according to the specifications established by Consob for the qualification of control chains. Above all, companies in the middle of the chain must hold stakes in the companies below them that is in any case less than $100 \%$. The qualification principle of the pyramidal group would not be needed if controlling interest were $100 \%$ due to the concentration of direct ownership. Secondly, these companies must be listed because a pyramidal group can only overcome the limits in the capital of its controlling shareholders, thanks to the resources gathered among the shareholders at the different levels of the pyramidal chain, if it is listed on the stock market ${ }^{8}$. If an unlisted company were to be introduced into the control chain, the group would represent a generic coalitional phenomenon rather than a specific method for the separation of ownership and control.

With regards to non-voting shares, as a measure of the degree of separation between voting rights and ownership rights, the voting rights lever $\left(L_{V R}\right)$ was used which, as noted corresponds to the ratio between voting rights and cash flow rights or:

\footnotetext{
${ }^{8}$ Pyramidal groups made up of only one listed company and horizontal groups involving companies that, even though subject to the same control, do not reveal control relationships among themselves, were excluded from this analysis.
} 


$$
L_{V R}=\frac{q_{V R}}{q_{C R}}
$$

indicating $q_{V R}$ as the percentage of voting rights held by the shareholder and $q_{C R}$ as the percentage of cash flow rights owned by the shareholder.

The control lever $\left(L_{C}\right)$ which measures the amount of capital controlled by each unit of capital invested was also considered or even:

$$
L_{C}=\frac{1}{q_{C R}}
$$

equivalent to:

$$
L_{C}=\frac{1}{q_{V R}} \times \frac{1}{(1-N V)}
$$

having defined $N V$ the percentage of non-voting shares present in the company's shareholding structure.

This ratio allows the measuring of the effect that the voting rights lever $\left(L_{V R}\right)$ produces on the amount controlled by each unit of invested capital. In fact, considering that $(1-N V)$ is equal to the percentage of shares with voting rights within the company $(V R)$, the equation (3) can be written, thus:

$$
L_{C}=\frac{1}{q_{V R}} \times \frac{1}{V R}
$$

and given that $q_{C R}=q_{V R} \times(1-N V)$, namely $q_{C R}=q_{V R} \times V R$, then:

$$
L_{V R}=\frac{q_{V R}}{q_{V R} \times V R}
$$

where $L_{V R}$ is equal to $\frac{1}{V R}$ and therefore, for equation (4), it can be expressed as follows:

$$
L_{C}=\frac{1}{q_{V R}} \times L_{V R}
$$

Having said all this, the difference between $L_{V R}$ and $L_{C}$ is the following: being the measure of separation between voting rights and cash flow rights, the $L_{V R}$ is a characteristic of the company and is equal for all shareholders. While its effects, measured by $L_{C}$, are different depending on the percentage of voting rights $\left(q_{V R}\right)$ held by the shareholder. The following example explains this.

If the the company's voting rights amount to $50 \%$ of the capital, $L_{V R}$ is equal to 2 for all shareholders; on the contrary, the effect of the $L_{C}$ that the $L_{V R}$ produces on each individual shareholder is 6.67 units of controlled capital for each unit of capital that is invested if $30 \%$ of voting rights is held, or equal to 5 if $40 \%$ of voting rights is held.

For shareholders agreements, the measurement of the separation between ownership and control is uniquely based on the $L_{C}$ of the first shareholder, since the $L_{V R}$ would be meaningless. In fact, the syndicate vote can be considered as an atypical device of separation between ownership and control, as it does not generate separation of voting rights from cash flow rights but instead produces an increase of the controlling value, or in other words in the usefulness of the voting rights held by adherents. Thus for example, the higher value can be carried out with the appointments of the Board of Directors.

Think of the case whereby the major shareholder that holds $31 \%$ of voting rights stipulates a voting 
agreement with another two shareholders, each holding a share of $10 \%$ on ordinary capital, which gives a syndicate total of $51 \%$. On the strength of the amount contributed by the agreement, the majority shareholder will control $60 \%$ of the pact while the other two will control $20 \%$ respectively. This distribution will probably also reflect upon the appointments of the directors due to the higher value control guaranteed by the agreement so if the number of directors to appoint is 10, unless otherwise agreed, 6 appointments lie with the majority shareholder and 2 for the others adherent respectively. However, the voting rights lever, being the ratio between voting rights and cash flow rights, does not change as a result of the agreement since for the largest shareholder, the percentage of voting rights, as well as the rights to cash flow is always equal to $31 \%$, in the presence and absence of the agreement.

In pyramidal companies, shareholding chains allow for voting rights to be separated from cash flow rights, to the total advantage of the controlling shareholder. This is even more true when dealing with longer and more complex control chains. A more extensive control chain thus determines the degree of capital dilution, also called alpha dilute $\left(\alpha_{d}\right)$, equivalent to the product of controlling shareholdings present in the pyramidal structure, meaning:

$$
\alpha_{d}=\prod_{i}^{n} q_{C R_{i}}
$$

or, in terms of the amount of ordinary capital:

$$
\alpha_{d}=\prod_{i}^{n} q_{V R_{i}}\left(1-N V_{i}\right)
$$

having defined the amount of cash flow rights as $q_{C R_{i}}$, the amount of ordinary capital as $q_{V R_{i}}$, and the per cent of non-voting shares of the company $i$ as $N V_{i}$.

The quantity expressed in this way, also called integrated ownership, is nothing more than the subsidiary's percentage of cash flows that the parent company receives in accordance to the number of direct or indirect shares held (Brealey, Myers, Allen, \& Sandri, 2007).

The reciprocal of integrated ownership constitutes the control lever, which can be written as:

$$
L_{C}=\frac{1}{\alpha_{d}}
$$

which, using equation (7), it can be written as:

$$
L_{C}=\frac{1}{\prod_{i}^{n} q_{C R_{i}}}
$$

or, using equation (8), it can also be written as:

$$
L_{C}=\frac{1}{\prod_{i}^{n} q_{V R_{i}}\left(1-N V_{i}\right)}
$$

Which represents the lever generated by the amount of ordinary capital held by the controlling company and by the non-voting shares along the pyramid chain. 
For this purpose, it is necessary to determine the Voting Rights Lever, expressed as:

$$
L_{V R}=\frac{q_{V R_{G}}}{\prod_{i}^{n} q_{V R_{i}}\left(1-N V_{i}\right)}
$$

Having defined the group ownership or the voting rights being totally held by the controlling shareholder as $q_{V R_{G}}$.

The weakest link principle has been adopted here in that the ultimate control rights of any shareholder are determined by the minimum value of indirect shareholdings along the control chain.

Thus, the voting rights lever allows the reconstruction of the different elements that compete for control, distinguishing the effect generated by the amount of ordinary shares held in the consecutive levels of the control chain, or rather $\frac{1}{n}$; the effect generated by the percentage of limited voting shares present in the pyramidal $\prod_{i}^{n} q_{V R_{i}}$

group's companies, or rather $\frac{1}{n}$; the effect generated by group ownership $q_{O_{G}}$, as the real amount of $\prod_{i}^{n}\left(1-N V_{i}\right)$

shareholdings held in the company at the bottom of the control chain and the minority shareholdings observed on the basis of the weakest link principle.

Thus, the voting rights lever in equation (12) is none other than the control lever multiplied by group ownership, that is:

$$
L_{V R}=L_{C} \times q_{V R_{G}}
$$

Finally, considering that for each of these three mechanisms of separation, the findings have concerned the entire population in which the mechanism is present. The main characteristics of the observations were synthesised with indexes of univariate descriptive statistics represented by measures of frequency (absolute and relative), estimates of central tendency (mean, median), measures of variance (standard deviation, coefficient of variance and range) and measures of form (difference between mean and median). For each device and each reference year, the relative outliers were determined using the interquartile analysis method, identifying the values greater and lower than 1.5 times the interquartile range and then comparing them to the first and third quartile respectively.

\section{Non-voting Shares}

The first important legislation in Italy on limited voting shares can be seen in Law No. 216, 1974 that established the dual-class company through the introduction of savings shares.

In fact, some new shares are issued without voting rights in exchange for more ownership rights than those granted by traditional shares ${ }^{9}$. From 1999 to 2007, approximately 30 years after they were introduced into the Italian market, limited voting shares, have shown, year after year, a progressive decline, however, as we shall see,

\footnotetext{
${ }^{9}$ In terms of both a share in the profits, given the minimum amount of profitability guaranteed, and privileges in the case of extraordinary events within the company, with the pre-emption right of being reimbursed shares at par value in the event the company should be close down.
} 
only partly due to operations of conversion from one class to dual class. Both the capitalization and the number of dual-class companies on the market decreased from $49.71 \%$ (capitalization) and $27.78 \%$ (number) in the first year to $35.96 \%$ (capitalization) and $10.76 \%$ (number) in the last year, as it can be seen in Table 1.

In each year observed, the phenomenon particularly affected companies with higher capitalization on account of the positive differential between incidence in terms of capitalization and incidence in terms of number.

Table 1

Dual-Class Companies

\begin{tabular}{|c|c|c|c|c|c|c|c|c|c|c|c|c|}
\hline \multirow{3}{*}{ Year } & \multicolumn{2}{|c|}{ Dual class companies } & \multicolumn{2}{|c|}{ Incidence on market } & \multicolumn{4}{|c|}{ Dual class companies } & \multicolumn{4}{|c|}{ Market } \\
\hline & \multirow{2}{*}{ No. } & \multirow{2}{*}{$\begin{array}{l}\text { Market cap. } \\
(\mathrm{m} €)\end{array}$} & \multirow{2}{*}{$\begin{array}{l}\text { Stock market } \\
\text { companies }\end{array}$} & \multirow{2}{*}{$\begin{array}{l}\text { Market } \\
\text { cap. (\%) }\end{array}$} & \multicolumn{2}{|c|}{ Large cap } & \multicolumn{2}{|c|}{ Small-medium cap } & \multicolumn{2}{|c|}{ Large cap } & \multicolumn{2}{|c|}{ Small-medium cap } \\
\hline & & & & & No. & Incidence & No. & Incidence & No. & Incidence & No. & Incidence \\
\hline 1999 & 75 & 357,725 & $27.78 \%$ & $49.71 \%$ & 37 & $49.33 \%$ & 38 & $50.67 \%$ & 85 & $31.48 \%$ & 185 & $68.52 \%$ \\
\hline 2000 & 63 & 353,353 & $21.21 \%$ & $43.18 \%$ & 30 & $47.62 \%$ & 33 & $52.38 \%$ & 97 & $32.66 \%$ & 200 & $67.34 \%$ \\
\hline 2001 & 57 & 247,533 & $19.39 \%$ & $41.79 \%$ & 32 & $56.14 \%$ & 25 & $43.86 \%$ & 91 & $30.95 \%$ & 203 & $69.05 \%$ \\
\hline 2002 & 56 & 188,426 & $18.98 \%$ & $41.14 \%$ & 29 & $51.79 \%$ & 27 & $48.21 \%$ & 81 & $27.46 \%$ & 214 & $72.54 \%$ \\
\hline 2003 & 48 & 204,232 & $17.20 \%$ & $40.82 \%$ & 24 & $50.00 \%$ & 24 & $50.00 \%$ & 77 & $27.60 \%$ & 202 & $72.40 \%$ \\
\hline 2004 & 46 & 236,107 & $16.55 \%$ & $40.65 \%$ & 19 & $41.30 \%$ & 27 & $58.70 \%$ & 82 & $29.50 \%$ & 196 & $70.50 \%$ \\
\hline 2005 & 44 & 261,139 & $15.60 \%$ & $38.60 \%$ & 17 & $38.64 \%$ & 27 & $61.36 \%$ & 89 & $31.56 \%$ & 193 & $68.44 \%$ \\
\hline 2006 & 41 & 292,423 & $13.18 \%$ & $37.56 \%$ & 13 & $31.71 \%$ & 28 & $68.29 \%$ & 84 & $27.01 \%$ & 227 & $72.99 \%$ \\
\hline 2007 & 37 & 284,239 & $10.76 \%$ & $38.75 \%$ & 12 & $32.43 \%$ & 25 & $67.57 \%$ & 87 & $25.29 \%$ & 257 & $74.71 \%$ \\
\hline Mean & 52 & 269.464 & $17.85 \%$ & $41.36 \%$ & 24 & $44.33 \%$ & 28 & $55.67 \%$ & 86 & $29.28 \%$ & 209 & $70.72 \%$ \\
\hline
\end{tabular}

Notes. The first three columns of the table show the number of companies with dual-class shares, their total capitalization, their incidence on the number and capitalization of the Italian stock exchange; the others report the incidence of the large and small-medium capitalization companies for the dual class and the market on the total number respectively of the dual class companies and the market companies.

The main use of dual class systems of such companies is proved by the comparison (see Table 1) between the incidence of companies with higher capitalisation on the total number of dual class companies and the same incidence related to the market itself, considering 800 million (1,000 from 2005) as the separation value between larger companies and others used by the Italian Stock Market to identify the Blue Chip segment. Compared to the entire stock market, dual class companies present a higher incidence of the larger companies during the entire reference period.

At the same time, the weight of limited voting shares on the market decreased with a differentiated trend between savings shares and preference shares, given the growth of preference shares compared to the net reduction of savings shares.

This means that dual-class companies preferred to reduce the larger part of limited voting shares, made up of savings shares, also because preference shares have always represented a minor part of share capital, making up for less than one per cent of the market. Individual dual-class companies were analyzed in order to determine if the reasons behind this trend can be attributed to the decision of the majority shareholder to change the shareholding structure or to other reasons attributed to the structure in itself. Of the 51 dual-class companies (present only in a part of the entire period) that reported a change, 16 result as mergers with other companies ${ }^{10}, 11$

10 Acquedotto De Ferrari, Banca Commerciale, Bonaparte, Caffaro, Cementeria di Barletta, Compart, Gim, La Fondiaria, Magneti Marelli, Montedison, Olivetti, Pirelli, Ras, Risanamento, Tim, San Paolo. 
as full takeovers ${ }^{11}, 16$ as conversions into ordinary capital ${ }^{12}, 1$ case which lacked compliance with pricing requirements ${ }^{13}, 1$ bankruptcy $^{14}, 5$ new companies joining the group in the reference period ${ }^{15}, 1$ new company joining the group in the reference period and subsequent delisting for a tender offer to acquire the entire share capital $^{16}$.

Thus, the reduction recorded on the whole of dual-class companies in the period of reference can be attributed mostly to reasons outside the shareholding structure, which are related more to merger and acquisitions and delisting operations.

The descriptive analysis based on the comparison between mean and median highlights both for cash flow rights and for voting rights a skew that is extremely reduced (see Table 2). In particular, cash flow rights show that the skew is positive and has slightly increased during the years of 1999, 2000, 2001, 2002 and $2005^{17}$ due to elevated values. Whereas for voting rights the skew is positive and has slightly increased in the years 1999, 2000 and 2005 due to the presence of extremely high values ${ }^{18}$, while it resulted negative and slightly increased during the years 2004, 2006 and 2007 due to the presence of extraordinarily low values ${ }^{19}$. The analysis also shows a marked dispersion of values of cash flow rights and voting rights due to the high value of the standard deviation and the coefficient of variation, on average about $34.48 \%$ for cash flow rights and $32.10 \%$ for the voting rights respectively.

Moreover, the minimum and maximum values of cash flow rights and voting rights cause a large range in different years, given the maximum value of 100 relative to the totalitarian holding of ordinary by Giovanni Agnelli in IFI (as well as the holding of the Fondazione Banco di Sardegna in Banco di Sardegna for 1999 and 2000). In any case, the difference between the two index positions leads to consider the median, a more appropriate measure of central trend in order to summarize the phenomenon in different years.

The median of cash flow rights is relatively stable at around 43\%, ranging from a minimum of 41.3 in 1999 to a maximum of 55.99 in 2000 . The combined reading of these values shows that the dual class structure was adopted by companies with a concentrated ownership, in which the first shareholder holds a little more than $50 \%$

\footnotetext{
11 Banco di Napoli, Bna, Bnl, Burgo, Ciga, Falck, La Rinascente, Marzotto, Saiag, Snia, Toro.

12 Aedes, Alleanza, Caltagirone, Cir, Cofide, Finmeccanica, Fullsix, Ifis, Intek, Italjolly, Linificio, Mondadori, Pinifarina, Recordati, Sopaf, Terme Acqui-Finnat.

13 Base-Holding.

14 Fin.Part.

15 Banca Carige, Edison, Iride, M\&C, Telecom Italia Media.

16 Partecipazioni Italiane.

17 In 1999, in many companies the first shareholder holds a share of cash flow rights which is more than 70\%, as Banco di Sardegna (84.03\%), Cementeria Barletta (76.59\%), Banca Monte dei Paschi di Siena (73.21\%), Banca Commerciale Italiana (70.33\%). In 2000 in Banco di Napoli the majority shareholder holds 91.33\% of cash flow rights, in Banco di Sardegna 84.03\%, in Falck 83.62\%. In 2001particularly elevated cash flow rights were recorded in Montedison (89.24\%), Banco di Napoli (93.25\%) and Banca Monte dei Paschi di Siena (65.9\%). In 2005 in Partecipazioni Italiane the majority shareholder holds 89.99\% of cash flow rights, In Borgosesia $78.24 \%$ and in Ras $76.19 \%$.

${ }^{18}$ In addition to shareholders that possess $100 \%$ of common stock as in IFI (for the period of 1999-2007) and in Banco di Sardegna (for the period of 1999-2000), in 1999 in many companies voting rights were very close to 100\%, as in IFIS (97.6\%) and Risanamento Napoli (90\%). In 2000 the holdings possessed by the majority shareholder were still very high in Banco di Napoli (97.61\%) and Falck (83.69\%). In 2005 in Acquedotto de Ferrari Galliera the major amount of common stock was equal to 97.76\%, in Partecipazioni Italiane 90\%, in Borgosesia 83.46\%.

${ }_{19}$ In 2004 in Telecom Italia voting rights of the controlling shareholder are equal to $17.03 \%$, in Impregilo at $20.33 \%$; also in 2006 the stakes of voting rights particularly contained are noted in Telecom Italia, equal to $18.01 \%$ and in Premuda, $28.81 \%$, as well as Marzotto, equal to 16.24\%; in 2007 in Seat Pagine Gialle the controlling quote was equal to 19.17\% of voting rights.
} 
of the ordinary capital $\left(q_{V R}\right)$ and little less than $50 \%$ of total company capital $\left(q_{C R}\right)$. Consequently, it can be deduced that the dual class shares is generally conceived by shareholders not in order to gain control of the company but rather to consolidate their actual controlling position whilst however detaining more than $50 \%$ of voting rights.

Table 2

Ownership and Control in Dual Class Companies

\begin{tabular}{|c|c|c|c|c|c|c|c|c|c|c|c|c|}
\hline \multirow[b]{2}{*}{ Year } & \multicolumn{6}{|c|}{ Cash flow rights } & \multicolumn{6}{|c|}{ Voting rights } \\
\hline & Mean & Median & $\begin{array}{l}\text { Std. } \\
\text { deviation }\end{array}$ & $\mathrm{CV}$ & Min. & Max. & Mean & Median & $\begin{array}{l}\text { Std. } \\
\text { deviation }\end{array}$ & $\mathrm{CV}$ & Min. & Max. \\
\hline 1999 & 43.63 & 41.30 & 14.97 & 34.31 & 15.29 & 84.03 & 57.24 & 55.00 & 18.12 & 31.66 & 15.63 & 100.00 \\
\hline 2000 & 45.68 & 43.88 & 16.02 & 35.07 & 15.29 & 91.34 & 59.30 & 55.99 & 18.91 & 31.89 & 15.63 & 100.00 \\
\hline 2001 & 44.12 & 42.84 & 14.94 & 33.86 & 19.88 & 20.33 & 54.61 & 54.95 & 16.51 & 30.24 & 20.33 & 100.00 \\
\hline 2002 & 45.56 & 42.66 & 16.79 & 36.85 & 19.88 & 20.33 & 55.52 & 55.23 & 16.62 & 29.94 & 20.33 & 100.00 \\
\hline 2003 & 44.55 & 44.95 & 13.76 & 30.89 & 12.25 & 17.03 & 55.03 & 55.55 & 16.63 & 30.22 & 17.03 & 100.00 \\
\hline 2004 & 42.48 & 42.46 & 15.09 & 35.52 & 10.91 & 17.03 & 51.66 & 54.50 & 17.26 & 33.41 & 17.03 & 100.00 \\
\hline 2005 & 46.66 & 44.17 & 17.49 & 37.48 & 12.41 & 18.01 & 55.87 & 53.19 & 19.78 & 35.41 & 18.01 & 100.00 \\
\hline 2006 & 43.09 & 43.10 & 15.09 & 35.02 & 12.42 & 16.24 & 51.36 & 53.38 & 17.87 & 34.80 & 16.24 & 100.00 \\
\hline 2007 & 42.95 & 42.91 & 13.45 & 31.32 & 16.27 & 19.17 & 51.91 & 52.26 & 16.29 & 31.38 & 19.17 & 100.00 \\
\hline Mean & 44.30 & 43.14 & 15.29 & 34.48 & 14.95 & 33.72 & 54.72 & 54.45 & 17.56 & 32.10 & 17.71 & 100.00 \\
\hline
\end{tabular}

Note. The table reports the values of the mean, the median, the standard deviation, the coefficient of variation, the minimum and the maximum of the cash flow rights and the voting rights held by the largest shareholder.

It is from this that the substantial stability of share leverage in the years is followed, owing to the value of the median of $L_{C}$ that fluctuates between a minimum of 2.22 and a maximum of 2.42, as on the other hand the value of the median of $L_{V R}$ which varies between a minimum of 1.11 and a maximum of 1.22 (see Table 3 ).

Table 3

Levers in Dual-Class Companies

\begin{tabular}{|c|c|c|c|c|c|c|c|c|c|c|c|c|}
\hline \multirow[b]{2}{*}{ Year } & \multicolumn{6}{|c|}{$L_{C}$} & \multicolumn{6}{|c|}{$L_{V R}$} \\
\hline & Mean & Median & $\begin{array}{l}\text { Std. } \\
\text { deviation }\end{array}$ & CV & Min. & Max. & Mean & Median & $\begin{array}{l}\text { Std. } \\
\text { deviation }\end{array}$ & CV & Min. & Max. \\
\hline 1999 & 2.60 & 2.42 & 1.05 & 40.29 & 1.19 & 6.54 & 1.37 & 1.22 & 0.43 & 31.32 & 1.00 & 3.46 \\
\hline 2000 & 2.48 & 2.28 & 0.97 & 39.15 & 1.09 & 6.54 & 1.36 & 1.20 & 0.45 & 33.01 & 1.00 & 3.46 \\
\hline 2001 & 2.50 & 2.33 & 0.81 & 32.36 & 1.07 & 5.03 & 1.28 & 1.11 & 0.31 & 24.38 & 1.00 & 2.00 \\
\hline 2002 & 2.49 & 2.34 & 0.91 & 36.43 & 1.07 & 5.03 & 1.27 & 1.11 & 0.31 & 24.65 & 1.00 & 2.00 \\
\hline 2003 & 2.59 & 2.22 & 1.32 & 51.12 & 1.57 & 8.16 & 1.27 & 1.18 & 0.31 & 24.33 & 1.00 & 2.00 \\
\hline 2004 & 2.79 & 2.35 & 1.50 & 53.83 & 1.28 & 9.17 & 1.25 & 1.16 & 0.29 & 23.15 & 1.00 & 1.99 \\
\hline 2005 & 2.53 & 2.26 & 1.29 & 51.02 & 1.11 & 8.06 & 1.23 & 1.14 & 0.29 & 23.46 & 1.00 & 1.99 \\
\hline 2006 & 2.73 & 2.32 & 1.41 & 51.53 & 1.37 & 8.05 & 1.22 & 1.12 & 0.28 & 22.77 & 1.00 & 1.99 \\
\hline 2007 & 2.62 & 2.33 & 1.07 & 40.65 & 1.44 & 8.05 & 1.24 & 1.13 & 0.29 & 22.99 & 1.00 & 1.99 \\
\hline Mean & 2.59 & 2.32 & 1.15 & 44.04 & 1.24 & 7.18 & 1.28 & 1.15 & 0.33 & 25.56 & 1.00 & 2.32 \\
\hline
\end{tabular}

Note. The table reports the values of the mean, the median, the standard deviation, the coefficient of variation, the minimum and the maximum of the control lever and the voting rights lever.

Moreover, the dispersion measured in cash flow rights and voting rights is reflected in a less pronounced dispersion of the levers, as shown in the coefficient of variation ranging between 32.36 and $53.83 \%$ for the $L_{C}$ and 
between 22.77 and $33.01 \%$ for the $L_{V R}$.

In addition to dispersion, the levers show the skew between means and medians in several years, the origins of which are reconstructed with the analysis of outliers.

In 1999, with reference to the $L_{V R}$ the distortion is produced by Borgosesia, whose value is 3.46, due to the high proportion of limited voting shares of around $71 \%$, and with reference to $L_{C}$ the distortion is produced by Fiat, equal to 4.70 and Impregilo equal to 6.54 , due to cash flow rights held by the largest shareholder being particularly low and amounted to $21.29 \%$ (Fiat) and $15.29 \%$ (Impregilo).

In 2000, Borgosesia, still has abnormal values for the $L_{V R}$ (3.46) and for the $L_{C}$ (4.24) due to the large percentage of non-voting shares. The $L_{C}$ values keep anomalous in Fiat and Impregilo, equal to 4.46 and 6.54 respectively.

In 2001, the outlier identified is only the value of $L_{C}$ in Impregilo (5.03).

In 2002, the distribution of values do not have outliers.

In 2003, with respect to the $L_{V R}$, particularly high values are found again in Borgosesia (2), while with respect to the $L_{C}$, extremely high values are found in Fiat (4.01) and in Impregilo (5.03).

In 2004, unusual large values of $L_{V R}$ are Danieli \& C., equal to 1.99, and IFI equal to 1.89 , due to the high amount of non-voting share, respectively of $47 \%$ and $49 \%$ of share capital, which ensures the control respectively of $53 \%$ and $100 \%$ of the voting rights, and cash flow rights amounting to $27 \%$ and $53 \%$. For the $L_{C}$ Telecom Italia is the outlier with a value of 9.17, as the result of extremely low cash flow rights equal to $10.91 \%$.

In 2005, the $L_{V R}$ values are still high in IFI and Danieli \& C. (1.99 and 1.89 respectively), and the $L_{C}$ in Telecom Italia (8.06).

In 2006, in addition to the same outliers in 2005 for the $L_{V R}$ and $L_{C}$, there is an unusual high $L c$ value in Marzotto equal to 6.44, given cash flow rights of $15.63 \%$.

In 2007, distortions in $L_{V R}$ are again caused by Danieli \& C. with a value of 1.99, and IFI for a value of 1.89, while in $L_{C}$ the distortions can be attributed to Telecom Italy, equal to 6.15.

The analysis of the levers averages and medians for the two classes of capitalization (large cap. and small-medium cap.) does not show a superiority of the values for the large cap. (see Table 4). However, the absence of a relationship between firm size and leverage is confirmed by the regression analysis performed between the $L_{V R}$ and capitalization, which is not statistically significant for both the linear model and the non-linear model. The statistical evidence thus leads to the conclusion that the intensity of the lever in the dual class is not dependent on the market value.

Hence, in its entirety, the implementation of the dual class structure by majority shareholders of Italian companies to separate voting rights from cash flow rights shows modest changes within the period studied. As demonstrated, the recorded downturn in terms of number and market capitalisation is to be attributed only in part to reconversion operations from dual class to one class. In the same way, no variations have been found affecting the intensity of the separation, as demonstrated by the series of the median values of the lever, and the the dispersion of the data, remaining high throughout the investigation period. On the contrary, each year observed, confirmed the increased use of dual class structure by larger companies, while the intensity of the lever is almost undifferentiated between large and small companies. 
Table 4

Levers in Large and Small-Medium Dual Class Companies

\begin{tabular}{|c|c|c|c|c|c|}
\hline \multicolumn{6}{|c|}{ Dual class } \\
\hline \multirow{2}{*}{ Year } & & \multicolumn{2}{|c|}{$L_{C}$} & \multicolumn{2}{|c|}{$L_{V R}$} \\
\hline & & Large cap & Small & Large cap & Small \\
\hline \multirow{2}{*}{1999} & Mean & 2.55 & 2.62 & 1.30 & 1.32 \\
\hline & Median & 2.45 & 2.21 & 1.15 & 1.22 \\
\hline \multirow{2}{*}{2000} & Mean & 2.38 & 2.60 & 1.30 & 1.44 \\
\hline & Median & 2.22 & 2.38 & 1.17 & 1.21 \\
\hline \multirow{2}{*}{2001} & Mean & 2.03 & 2.23 & 1.17 & 1.31 \\
\hline & Median & 1.96 & 2.27 & 1.09 & 1.31 \\
\hline \multirow{2}{*}{2002} & Mean & 2.06 & 2.19 & 1.18 & 1.27 \\
\hline & Median & 1.82 & 2.27 & 1.05 & 1.15 \\
\hline \multirow{2}{*}{2003} & Mean & 2.61 & 2.56 & 1.21 & 1.36 \\
\hline & Median & 2.25 & 2.22 & 1.12 & 1.20 \\
\hline \multirow{2}{*}{2004} & Mean & 2.75 & 2.64 & 1.23 & 1.26 \\
\hline & Median & 2.21 & 2.35 & 1.12 & 1.18 \\
\hline \multirow{2}{*}{2005} & Mean & 2.42 & 2.42 & 1.25 & 1.23 \\
\hline & Median & 2.42 & 2.21 & 1.16 & 1.09 \\
\hline \multirow{2}{*}{2006} & Mean & 2.69 & 2.75 & 1.22 & 1.18 \\
\hline & Median & 2.33 & 2.26 & 1.13 & 1.03 \\
\hline \multirow{2}{*}{2007} & Mean & 2.81 & 2.25 & 1.30 & 1.03 \\
\hline & Median & 2.52 & 2.21 & 1.17 & 1.04 \\
\hline
\end{tabular}

Note. The table shows the mean and the median values of the control lever and voting rights lever for the dual class companies with large and small-medium capitalization.

\section{Shareholder Agreements}

Shareholder agreements are contracts that are stipulated between shareholders, in the margin of the certificate of incorporation and of the statute. Article number 122 of the Draghi Reform Act regulates agreements "stipulated in any way whatsoever, that contain the exercise of voting rights in a listed joint stock company and in the companies controlled”, defining the duties of communication, the length of time and the right to withdraw ${ }^{20}$. The introduction of these provisions in 1998 represented an innovation for Italian law in this field considering that the previous regulations, both fragmented and sectorial, were not clear as to their legitimacy

Agreements may take on different forms according to the different commitments and obligations foreseen for the parties involved ${ }^{21}$. The most important agreements in terms of control are voting agreements, which are agreements that, along with the deed of incorporation and the articles of association, shareholders sign agreeing to vote together for a specific period of time in order to pursue ends that meet their needs. In particular, these types of contracts are generally drawn up to regulate the methods with which the parties involved must exercise

\footnotetext{
20 The agreement must be communicated to Consob, registered with the Italian company register and published in an Italian national newspaper. The syndicate has a legal duration of three years with the possibility of renewal. With reference to the right to recede, advanced notice is not mandatory in the presence of a takeover or totalitarian exchange, or preventive, anticipated.

21 Article 122 of the Draghi Reform Act allows the use of agreements that institute obligations of preventive consultation for the exercise of the right to vote within the company with listed shares and in the companies that control them; that put a transfer limit of the relative shares or of financial instruments assigning rights to purchase or to underwrite them; that anticipate the purchase of the relative shares or financial instruments, having for subject or for effect the dominating influence on companies.
} 
their voting rights on specific issues ${ }^{22}$. In any case, consultation agreements are the least constraining, requiring consultation before making certain company decisions and leaving the shareholder full freedom in exercising voting rights. Agreements, thus, have significant effects. Blocking agreements are particularly important with regards to contestability and aim at conditioning the transfer of shares and defining corporate structure, discouraging the entry of new shareholders and thus advising against changes in company control through takeover bids.

In this case, the agreement demotivates the shareholder from transferring shares to eventual third parties, given that the eventual transfer could bring about actions for damages.

Therefore the agreements represent a prominent and disparate set within the market considering that as a whole they concern a little less than a third of the entire capitalisation of the Italian stock market.

In particular this paper points out that there is a greater number of agreements than companies affected by this phenomenon. Some companies, in fact, are the subject of several shareholder agreements so from an average of 101 agreements per year it results an incidence of $27.77 \%$ and $31.94 \%$ in terms of number and market capitalization respectively (see Table 5).

Table 5

Shareholder Agreements

\begin{tabular}{|c|c|c|c|c|c|c|c|c|c|c|c|}
\hline \multirow{3}{*}{ Year } & \multicolumn{3}{|c|}{ Shareholder agreements } & \multicolumn{4}{|c|}{$\begin{array}{c}\text { Companies subject to } \\
\text { shareholder agreements }\end{array}$} & \multicolumn{4}{|c|}{$\begin{array}{l}\text { Companies subject to a } \\
\text { controlling agreements }\end{array}$} \\
\hline & \multirow{2}{*}{$\begin{array}{l}\text { Total } \\
\text { No. }\end{array}$} & \multirow{2}{*}{$\begin{array}{l}\text { Direct } \\
\text { No. }\end{array}$} & \multirow{2}{*}{$\begin{array}{l}\text { Indirect } \\
\text { No. }\end{array}$} & \multicolumn{2}{|c|}{ Number } & \multicolumn{2}{|c|}{ Incidence } & \multicolumn{2}{|r|}{ Number } & \multicolumn{2}{|c|}{ Incidence } \\
\hline & & & & No. & $\begin{array}{l}\text { Market } \\
\text { cap. }(\mathrm{m} €)\end{array}$ & $\begin{array}{l}\text { Stock market } \\
\text { companies }\end{array}$ & $\begin{array}{l}\text { Market } \\
\text { cap. (\%) }\end{array}$ & No. & $\begin{array}{l}\text { Market } \\
\text { cap. }(\mathrm{m} €)\end{array}$ & $\begin{array}{l}\text { Stock market } \\
\text { companies }\end{array}$ & $\begin{array}{l}\text { Market } \\
\text { cap.(\%) }\end{array}$ \\
\hline 1999 & 75 & 63 & 12 & 73 & 218,986 & $27.04 \%$ & 30.14 & 38 & 123,058 & $14.07 \%$ & 16.94 \\
\hline 2000 & 90 & 71 & 19 & 81 & 210,734 & $27.27 \%$ & 25.75 & 46 & 128,125 & $15.49 \%$ & 15.66 \\
\hline 2001 & 103 & 82 & 21 & 86 & 153,371 & $29.25 \%$ & 25.89 & 47 & 100,160 & $15.99 \%$ & 16.91 \\
\hline 2002 & 91 & 71 & 20 & 75 & 123,867 & $25.42 \%$ & 27.05 & 47 & 67,705 & $15.93 \%$ & 14.78 \\
\hline 2003 & 93 & 67 & 26 & 78 & 186,285 & $27.96 \%$ & 38.22 & 48 & 121,998 & $17.20 \%$ & 25.03 \\
\hline 2004 & 99 & 68 & 31 & 81 & 208,408 & $29.14 \%$ & 35.88 & 48 & 149,792 & $17.27 \%$ & 25.79 \\
\hline 2005 & 107 & 77 & 30 & 69 & 265,747 & $24.47 \%$ & 39.28 & 46 & 173,569 & $16.31 \%$ & 25.65 \\
\hline 2006 & 118 & 75 & 43 & 98 & 300,000 & $31.51 \%$ & 38.54 & 56 & 215,703 & $18.01 \%$ & 27.71 \\
\hline $7^{200}$ & 130 & 74 & 56 & 96 & 210,972 & $27.91 \%$ & 26.69 & 63 & 130,249 & $18.31 \%$ & 16.48 \\
\hline Mean & 101 & 72 & 29 & 82 & 208,708 & $27.77 \%$ & 31.94 & 48 & 134,484 & $16.51 \%$ & 20.55 \\
\hline
\end{tabular}

Notes. In the first three columns the table shows the number of shareholder agreements drawn up in companies listed on the Italian stock exchange and the number of direct and indirect agreements. The other columns show the number and the capitalization of companies subject to shareholder agreements and their incidence on the number and the capitalization of the Italian stock market. The last column shows the number and the capitalization of controlling agreements (direct and indirect) and their incidence on the number and the capitalization of the stock exchange.

An average of $70 \%$ of shareholder agreements are direct agreements involving listed companies while the remaining 30\% includes indirect agreements involving unlisted companies that, however, control listed companies.

With regards to control agreements — in addition to those provided in the table — there is an average of 48 companies, of which 30 are subject to direct control agreements and 18 to indirect control agreements.

\footnotetext{
${ }^{22}$ For example, approving the budget, statutory modifications, particularly important strategic decisions as well as appointing people to positions, normally divided up among the parties to the agreement on the basis of the number of shares held.
} 
The average value on the whole of control agreements corresponds to one-fifth of market capitalization, of which $12 \%$ is represented by direct agreements and $8 \%$ by indirect agreements.

From an evolutionary point of view, the intensity of control agreements, in terms of capitalization, remained fairly constant in the first four years followed by a 25.03\% increase in 2003 and a $27.71 \%$ increase in 2006 (see Table 1). In the last year, market value reported a significant decrease, dropping to $16.48 \%$, despite the increase in the number of companies from 56 to 63. Consequently, it can be assumed that, the decline of the value in 2007 can be attributed to the termination of some agreements regarding high cap companies rather than to the phenomenon in itself. In fact, some of the companies with agreements that were terminated in that year include San Paolo, Banca Intesa and Capitalia, corresponding to approximately $11 \%$ of the entire market value.

Compared to the dual class, the agreements regardless of whether their nature be controlling or otherwise concern more companies, probably because of their greater versatility due to the fact that they answer to the needs of regulation of the various aspects of company life by simply providing specific covenants.

In contrast, agreements show a greater diffusion in larger companies, as it is the case with the dual class system. In fact, Table 6 shows that the adoption of shareholder agreements by these companies is more common in those with greater capitalisation considering that on average $66.5 \%$ come from the Blue Chip sector compared to the market average of $29.28 \%$.

Table 6

Shareholder Agreements: The Incidence of Large and Small-Medium Companies

\begin{tabular}{|c|c|c|c|c|c|c|c|c|c|c|}
\hline \multirow{3}{*}{ Year } & \multicolumn{5}{|c|}{ Market } & \multicolumn{5}{|c|}{ Shareholder agreements } \\
\hline & \multirow{2}{*}{ Total } & \multicolumn{2}{|c|}{ Large cap. } & \multicolumn{2}{|c|}{ Small-medium cap. } & \multirow{2}{*}{ Total } & \multicolumn{2}{|c|}{ Large cap. } & \multicolumn{2}{|c|}{ Small-medium cap } \\
\hline & & No. & Incidence & No. & Incidence & & No. & Incidence & No. & Incidence \\
\hline 1999 & 270 & 85 & $31.48 \%$ & 185 & $68.52 \%$ & 38 & 24 & $63.16 \%$ & 14 & $36.84 \%$ \\
\hline 2000 & 297 & 97 & $32.66 \%$ & 200 & $67.34 \%$ & 46 & 28 & $60.87 \%$ & 18 & $39.13 \%$ \\
\hline 2001 & 294 & 91 & $30.95 \%$ & 203 & $69.05 \%$ & 47 & 33 & $70.21 \%$ & 14 & $29.79 \%$ \\
\hline 2002 & 295 & 81 & $27.46 \%$ & 214 & $72.54 \%$ & 47 & 33 & $70.21 \%$ & 14 & $29.79 \%$ \\
\hline 2003 & 279 & 77 & $27.60 \%$ & 202 & $72.40 \%$ & 48 & 33 & $68.75 \%$ & 15 & $31.25 \%$ \\
\hline 2004 & 278 & 82 & $29.50 \%$ & 196 & $70.50 \%$ & 48 & 33 & $68.75 \%$ & 15 & $31.25 \%$ \\
\hline 2005 & 282 & 89 & $31.56 \%$ & 193 & $68.44 \%$ & 46 & 31 & $67.39 \%$ & 15 & $32.61 \%$ \\
\hline 2006 & 311 & 84 & $27.01 \%$ & 227 & $72.99 \%$ & 56 & 35 & $62.50 \%$ & 21 & $37.50 \%$ \\
\hline 2007 & 344 & 87 & $25.29 \%$ & 257 & $74.71 \%$ & 63 & 42 & $66.67 \%$ & 21 & $33.33 \%$ \\
\hline Mean & 294 & 86 & $29.28 \%$ & 209 & $70.72 \%$ & 49 & 32 & $66.50 \%$ & 16 & $33.50 \%$ \\
\hline
\end{tabular}

Note. The table reports the incidence of the large and small-medium capitalization companies for the companies subject to shareholder agreements and the market on the total number respectively of the companies subject to shareholder agreements and the market companies.

As already stated for the dual class structure, it is easy to explain the greater diffusion in larger companies due to the superior financial commitments that need to be faced by shareholders wishing to acquire control. In effect the higher amount of capital pushes investors that are interested in control towards the separation devices between ownership and control that allow them to limit financial commitment per unit of controlled capital to a more or less intense extent. Given their market relevance, above all larger companies attract investors that denote a particular capacity to constructing relations which as a natural consequence, are represented in many ways by shareholder agreements.

As already mentioned, shareholder agreements produce different effects than those generated by the other CEMs. This can be demonstrated by comparing the share of ordinary capital held by the major shareholder with 
the total amount of shares on voting rights of all adherents, as shown in Table 7.

Table 7

Ownership in Direct Shareholder Agreements

\begin{tabular}{|c|c|c|c|c|c|c|c|c|c|c|c|c|c|c|c|c|c|c|}
\hline \multirow{4}{*}{ Year } & \multicolumn{18}{|c|}{ Direct shareholder agreement } \\
\hline & \multicolumn{6}{|c|}{ Large shareholder } & \multicolumn{6}{|c|}{ Agreement } & \multirow{2}{*}{\multicolumn{3}{|c|}{$\begin{array}{c}\begin{array}{c}\text { Largest } \\
\text { shareholder }\end{array} \\
\begin{array}{c}\text { Degree of } \\
\text { control }\end{array}\end{array}$}} & \multicolumn{3}{|c|}{ Agreement } \\
\hline & \multicolumn{6}{|c|}{ Voting rights } & \multicolumn{6}{|c|}{ Voting rights } & & & & \multicolumn{3}{|c|}{ Degree of control } \\
\hline & Mean & Median & $\begin{array}{l}\text { Std. } \\
\text { deviation }\end{array}$ & $\mathrm{CV}$ & Min. & Max. & Mean & Median & $\begin{array}{l}\text { Std. } \\
\text { deviation }\end{array}$ & $\mathrm{CV}$ & Min. & Max. & $1^{\circ}$ & $2^{\circ}$ & $3^{\circ}$ & $1^{\circ}$ & $2^{\circ}$ & $3^{\circ}$ \\
\hline 1999 & 22.66 & 20.00 & 10.39 & 45.85 & 9.39 & 49.88 & 50.36 & 50.55 & 12.79 & 25.39 & 27.88 & 83.24 & - & 2 & 2 & 20 & 7 & 1 \\
\hline 2000 & 22.95 & 19.99 & 10.66 & 46.45 & 5.03 & 44.97 & 51.97 & 50.20 & 14.60 & 28.09 & 20.70 & 80.00 & - & - & 7 & 21 & 11 & 1 \\
\hline 2001 & 24.06 & 22.04 & 10.07 & 41.85 & 13.10 & 44.97 & 50.48 & 50.20 & 12.52 & 24.80 & 23.29 & 80.00 & - & - & 7 & 22 & 6 & 3 \\
\hline 2002 & 24.54 & 23.18 & 11.19 & 45.58 & 3.90 & 44.97 & 49.50 & 48.10 & 14.05 & 28.38 & 19.98 & 81.19 & - & - & 13 & 22 & 5 & 4 \\
\hline 2003 & 20.72 & 15.14 & 10.46 & 50.49 & 7.50 & 41.80 & 48.85 & 48.10 & 16.21 & 33.18 & 22.16 & 90.92 & - & - & 7 & 18 & 8 & 3 \\
\hline 2004 & 20.68 & 15.08 & 10.65 & 51.51 & 7.95 & 41.00 & 49.62 & 50.65 & 15.32 & 30.87 & 23.35 & 87.32 & - & 1 & 6 & 15 & 10 & 3 \\
\hline 2005 & 22.39 & 15.79 & 13.74 & 61.36 & 5.48 & 49.98 & 50.89 & 51.10 & 14.88 & 29.24 & 23.40 & 87.32 & - & 2 & 5 & 19 & 10 & 0 \\
\hline 2006 & 21.46 & 19.17 & 12.75 & 59.42 & 6.08 & 49.98 & 48.95 & 51.00 & 14.16 & 28.93 & 18.76 & 78.78 & - & 2 & 7 & 19 & 11 & 2 \\
\hline 2007 & 21.17 & 19.70 & 12.02 & 56.79 & 4.51 & 45.34 & 48.87 & 50.18 & 14.86 & 30.41 & 12.38 & 87.98 & - & 1 & 7 & 19 & 11 & 3 \\
\hline Mean & 22.29 & 18.90 & 11.33 & 51.03 & 6,99 & 45.88 & 49.94 & 50.01 & 14.38 & 28.81 & 21.32 & 84.08 & - & 2 & 7 & 19 & 9 & 2 \\
\hline
\end{tabular}

Note. The table shows the mean, the median, the standard deviation, the coefficient of variation, the minimum and the maximum of the cash flow rights and voting rights held by the largest shareholder in direct shareholder agreements.

In particular, regarding direct agreements the descriptive statistics demonstrate a positive skew in all the period of analysis with the comparison between the mean and the median of voting rights held by the major shareholder, owing to the presence of particularly high values ${ }^{23}$.

In relation to the total amount of syndicated holding, the skew is low and has a progression differing by its sign, negative in 1999, positive between 2000 and 2003 due to the presence of particularly high values ${ }^{24}$ and again negative between 2004 and 2007 owing to the presence of particularly low values ${ }^{25}$.

In addition, both for the shares held by the largest shareholder and for the total syndicated shares the analysis also shows a marked dispersion. The standard deviation and the coefficient of variation never fall below 10 and $29 \%$.

The maximum and minimum ranges is consistent within the different years. The majority share held by one single shareholder has a minimum of around $7 \%$ and a maximum of around $46 \%$ whilst the total of ordinary stock capital controlled has a minimum value of around $21 \%$ and a maximum value of around $84 \%$. These values show a heavy dispersal which is proved by the coefficient of variation of the majority shareholder's voting rights and of the agreement in its entirety that do not go below $41.85 \%$ and $24.8 \%$ respectively.

Given the difference, between the two position index, the median can be considered more correct in order to

\footnotetext{
${ }^{23}$ In the years 2005 and 2006, when the skew becomes more prominent, the largest shareholder held a share of 49.98 in Italjolly, 49.28\% in Euphon (2005 only), 46.97\% in IGD, 41.55\% in Dada.

${ }^{24}$ In 2000 the sum of shares of the agreement was 80\% in Digital Bros, 77.1\% in Eplanet, 75.08\% in Engeneering. In 2001 and 2002 the higher values were again represented by Digital Bros and Engeneering. In 2002, La Gaiana is added with 81.19\% and Cit with 75.55\%. In 2003 along with Digital Bros and La Gaiana, the highest value is represented by Manuli with $90.92 \%$.

${ }^{25}$ In 2004 more contained values are noted in Azimut, where the sum of the shares of the adherents is 23.35\% and Marzotto with 27.95\%. In 2005 along with Azimut, Impregilo with 27.36\%. In 2006 also Azimut shows a contained value of 22.7\%, to which San Paolo Imi is added with $18.76 \%$ and Capitalia with $25.84 \%$. In 2007, as well as Azimut, Società Cattolica Assicurazioni represents the minimum with $12.38 \%$.
} 
summarise the phenomenon for the different years.

The skew becomes more prominent for indirect agreements (see Table 8). The difference between mean and median for the majority shareholder's shares is positive in 2002, 2003, 2004, 2005 and 2006 due to the presence of particularly high values ${ }^{26}$ whilst it is negative in the remaining years ${ }^{27}$.

Table 8

Ownership in Indirect Shareholder Agreements

\begin{tabular}{|c|c|c|c|c|c|c|c|c|c|c|c|c|c|c|c|}
\hline \multirow{4}{*}{ Year } & \multicolumn{15}{|c|}{ Indirect shareholder agreement } \\
\hline & \multicolumn{6}{|c|}{ Large shareholder } & \multicolumn{6}{|c|}{ Agreement } & \multicolumn{3}{|c|}{$\begin{array}{c}\text { Large shareholder = } \\
\text { agreement }\end{array}$} \\
\hline & \multicolumn{6}{|c|}{ Voting rights } & \multicolumn{6}{|c|}{ Voting rights } & \multicolumn{3}{|c|}{ Degree of control } \\
\hline & Mean & Median & $\begin{array}{l}\text { Std. } \\
\text { deviation }\end{array}$ & $\mathrm{CV}$ & Min. & Max. & Mean & Median & $\begin{array}{l}\text { Std. } \\
\text { deviation }\end{array}$ & $\mathrm{CV}$ & Min. & Max. & $1^{\circ}$ & $2^{\circ}$ & $3^{\circ}$ \\
\hline 1999 & 52.51 & 58.06 & 22.09 & 42.07 & 17.49 & 93.82 & 54.43 & 58.23 & 23.31 & 42.83 & 17.49 & 93.82 & 6 & 2 & 2 \\
\hline 2000 & 52.44 & 53.26 & 21.03 & 40.10 & 25.29 & 93.60 & 52.80 & 53.43 & 21.10 & 39.96 & 25.29 & 94.93 & 10 & 3 & 2 \\
\hline 2001 & 48.05 & 52.53 & 14.09 & 29.32 & 26.96 & 75.06 & 48.37 & 52.63 & 14.04 & 29.03 & 27.77 & 75.28 & 10 & 4 & 2 \\
\hline 2002 & 57.95 & 54.89 & 21.58 & 37.24 & 26.96 & 93.14 & 58.26 & 54.97 & 21.71 & 37.26 & 27.77 & 93.14 & 11 & 4 & 1 \\
\hline 2003 & 58.25 & 61.30 & 15.34 & 26.33 & 12.25 & 79.95 & 58.56 & 61.30 & 15.37 & 26.25 & 17.03 & 82.44 & 16 & 1 & 2 \\
\hline 2004 & 58.39 & 60.07 & 15.39 & 26.36 & 17.03 & 90.03 & 59.17 & 61.55 & 16.60 & 28.05 & 17.03 & 97.66 & 17 & 1 & 2 \\
\hline 2005 & 57.29 & 57.53 & 14.81 & 25.85 & 18.01 & 75.26 & 57.41 & 57.53 & 14.90 & 25.95 & 18.01 & 75.26 & 14 & 1 & 2 \\
\hline 2006 & 55.08 & 54.93 & 12.91 & 23.44 & 22.23 & 96.86 & 55.30 & 55.01 & 13.02 & 23.54 & 18.01 & 72.53 & 19 & 0 & 4 \\
\hline 2007 & 54.85 & 56.21 & 14.53 & 26.49 & 72.53 & 96.86 & 55.18 & 56.74 & 14.58 & 26.42 & 23.60 & 96.86 & 22 & 4 & 3 \\
\hline Mean & 54.98 & 56.53 & 16.86 & 30.80 & 26.53 & 88.29 & 55.50 & 56.82 & 1718 & 31.03 & 21.33 & 86.88 & 14 & 2 & 2 \\
\hline
\end{tabular}

Note. The table shows the mean, the median, the standard deviation, the coefficient of variation, the minimum and the maximum of the cash flow rights and voting rights held by the largest shareholder in indirect shareholder agreements.

Voting rights within the agreements as a whole have a negative difference between mean and median for the entire period with the exception of 2002 and 2006 which result positive. As it is the case with direct agreements, the analysis shows a marked dispersion both for the shares held by the major shareholder and for the overall shares controlled, given the high value of the coefficient of variation. The minimum and maximum ranges determine a consistent range throughout the years. The majority share held by one single shareholder has a minimum of around $26 \%$ and a maximum of around $88 \%$ whilst the total of ordinary stock capital controlled has a minimum value of around $21 \%$ and a maximum value of around $86 \%$.

Given the difference between the two position index, the median can be still considered the more correct value in order to explain the trend of indirect agreements for the different years.

In summary, consistent with the results of the Gianfrate's (2007) investigation, the majority shareholder holds a little less than $20 \%$ while the coalition controls around $50 \%$ of voting rights for direct agreements. Indirect agreements however do not show prominent differences between the median share held by the majority

${ }^{26}$ In 2002 the controller of Calp holds a share of 92.04\%, the controller of La Rinascente holds a share of $93.14 \%$. In 2006 in Intek the majority shareholder held a share of $72.53 \%$ and in Edison held a share of $71.23 \%$.

${ }^{27}$ In 1999 and 2000 the minor value is assigned to Olivetti with a share held by the controller equal to $17.49 \%$ and 25.29 . In 2000 in addition the controller of Snia held a share of $28.84 \%$. In 2001, the most contained values are again represented by Olivetti and Snia. In 2003 a controlling interest particularly low is observed in Telecom Italia, due to the share of 17.03\% owned by Olympia, and in Ducati for the share of 33.53\% owned by TPG Advisors. In 2004 and 2005 the negatively skew is attributable to Telecom Italia and Ducati too. In 2007 the most contained values are represented by Interpump with a controlling share of $22.23 \%$ and Telecom Italia with 23.6\%. 
shareholder or controlling company and the controlling share that is reached by the aforementioned accord. In fact the agreements of this type are stipulated within companies that are not listed but which control listed companies and have absolute majority of the capital within the controlling company in almost all cases. An example such as Autostrade, who has been controlled by Schemaventotto with $30 \%$ of all shares since its privatisation in 1999. An indirect agreement was stipulated between its shareholders (Edizione Finance S.A., Fondazione Cassa di Risparmio di Torino, Acesa Italia S.r.l., UniCredito Italiano S.p.A., INA, Brisa Autostradas de Portugal S.A.) aimed at regulating the management and the organisation of Autostrade itself. As such, the controlling share of Schemaventotto is equal to $100 \%, 30 \%$ of which is held by Autostrade.

These conclusions are also supported by the change in the type of control made possible by the agreement. In fact, in companies subject to direct agreement, if the agreement is absent the single shareholder would generally posses a form of third level control, being able to adopt decisions during the second ordinary meeting convocation but not in extraordinary meetings. Undersigning an agreement generally gives the shareholder first level control (even if shared between the other adherents) with the capability of influencing decisions made both in ordinary and extraordinary meetings. Whereas within companies affected by indirect parties, generally it is not possible to separate between the type of the majority shareholder's control and that which is reached with an agreement because they are both equal at the first level.

Whenever the largest shareholder is not able to control the company with its own share, the analysis has brought forward that the direct shareholder agreement stipulated is aimed at obtaining control, to share obviously between all adherents. This is not the case however for indirect shareholder agreements where the objective is to regulate and stabilise relations between shareholders of the controlling company, considering that control of the target company is assured by the majority holding that is already held.

As it has already been highlighted in the Survey Methodology, the intensity of the separation between ownership and control is investigated only using the leverage $L_{C}$ which represents the quantity of the agreement's controlled capital for each unit of invested capital. Its values were calculated originating from Consob data and by considering the total amount of shares held by the shareholders within the agreement as the controlling share.

On this basis the analysis has highlighted (see Table 9):

- For direct agreements, it is found a median $L_{C}$ value that from 1.93 at the beginning of the period increases to 1.96 in 2007;

- For indirect agreements, it is found a reduction of the median $L_{C}$ value from 2.30 in 1999 to 1.76 in 2007.

In both cases, there is anyway a dispersed and highly skewed distribution of the observed data. In particular regarding the skew of direct agreements, analysis of the $L_{C}$ outliers demonstrated the following values capable of creating distortion on the mean for different years.

In 1999 the distortion is produced by Banca di Roma and San Paolo with $L_{C}$ values of 3.16 and 2.69 respectively caused by the sum of the particularly contained controlling shares being 31.47 and 36.44 respectively. In the same way La Gaiana's $L_{C}$ creates a distortion for its very low value of 1.2, considering the high value of the sum of the adherents' shares at $83.24 \%$.

In 2000 the outlier is depicted by Necchi with a $L_{C}$ equal to 4.85 which is caused by the sum of the controlling shares at $20.7 \%$. 
Table 9

Levers of Shareholder Agreements

\begin{tabular}{|c|c|c|c|c|c|c|c|}
\hline \multicolumn{8}{|c|}{$\overline{L_{C}}$} \\
\hline Year & Type of agreement & Mean & Median & Std. deviation & $\mathrm{CV}$ & Min & Max \\
\hline \multirow{2}{*}{1999} & Direct & 1.99 & 1.93 & 0.52 & 26.13 & 1.23 & 5.44 \\
\hline & Indirect & 2.66 & 2.30 & 1.34 & 50.38 & 1.07 & 5.83 \\
\hline \multirow{2}{*}{2000} & Direct & 2.01 & 1.88 & 0.89 & 44.28 & 1.25 & 5.07 \\
\hline & Indirect & 2.40 & 2.49 & 0.87 & 36.25 & 1.05 & 3.95 \\
\hline \multirow{2}{*}{2001} & Direct & 1.96 & 1.79 & 0.61 & 31.12 & 1.25 & 4.29 \\
\hline & Indirect & 2.35 & 2.08 & 0.71 & 30.21 & 1.33 & 3.60 \\
\hline \multirow{2}{*}{2002} & Direct & 2.08 & 1.83 & 0.97 & 46.63 & 1.23 & 5.44 \\
\hline & Indirect & 2.03 & 1.82 & 0.79 & 38.92 & 1.09 & 3.60 \\
\hline \multirow{2}{*}{2003} & Direct & 2.21 & 1.88 & 1.02 & 46.15 & 1.10 & 5.72 \\
\hline & Indirect & 2.12 & 1.66 & 1.52 & 71.70 & 1.21 & 8.16 \\
\hline \multirow{2}{*}{2004} & Direct & 2.21 & 2.00 & 0.86 & 38.91 & 1.15 & 4.28 \\
\hline & Indirect & 2.13 & 1.64 & 1.72 & 80.75 & 1.02 & 9.17 \\
\hline \multirow{2}{*}{2005} & Direct & 2.08 & 1.96 & 0.74 & 35.58 & 1.15 & 4.27 \\
\hline & Indirect & 2.18 & 1.74 & 1.59 & 72.94 & 1.33 & 8.06 \\
\hline \multirow{2}{*}{2006} & Direct & 2.31 & 1.96 & 0.90 & 38.96 & 1.35 & 4.79 \\
\hline & Indirect & 2.15 & 1.82 & 1.38 & 64.19 & 1.38 & 8.05 \\
\hline \multirow{2}{*}{2007} & Direct & 2.20 & 1.91 & 1.27 & 57.73 & 1.14 & 8.08 \\
\hline & Indirect & 2.12 & 1.76 & 1.06 & 50.00 & 1.03 & 6.15 \\
\hline Mean & & 2.17 & 1.86 & 1.16 & 53.23 & 1.23 & 6.57 \\
\hline
\end{tabular}

Notes. The table reports the values of the mean, the median, the standard deviation, the coefficient of variation, the minimum and the maximum of the control lever and voting rights lever calculated for direct and indirect control agreements.

In 2001 the $L_{C}$ in San Paolo Imi equals to 4.29 and is attributable to the cash flow rights concerning the sum of the controlling shares at $23.29 \%$.

As well as San Paolo Imi, with a $L_{C}$ value equal to 5.44 in 2002, Banca Antonia Popolare Veneta with a $L_{C}$ of 5 following cash flow rights regarding an agreement equal to $19.98 \%$.

San Paolo also figures within the outliers of 2003 with a value of 5.73. There is also a value of 4.17 for Marzotto due to cash flow rights of the controlling shares reaching $25.57 \%$.

There were no outliers for the year 2004.

In 2005, along with San Paolo Imi with a $L_{C}$ of 3.22, Capitalia also registers a dysfunctional $L_{C}$ of 3.05 which was caused by the reduced cash flow rights of the adherent shares within the agreement to $32.78 \%$, and Impregilo which returned a value of 3.66 and is attributable to cash flow shares on the entire controlling stake of $27.36 \%$.

Analysing the outliers for 2006 shows a $L_{C}$ value of 4.41 for Azimut as a consequence of a share on cash flow rights relative to the agreement at 22.7, and $4.79 L_{C}$ for Interpump owing to cash flow rights of the adhering shares to the agreement equal to $19.32 \%$.

Together with Azimut, having a $L_{C}$ value of 4.47, dysfunctional values are found for Reno de Medici with a $L_{C}$ of 3.51 due to all adherent controlling shares on cash flow rights being 27.74, and also for Società Cattolica Assicurazioni with a $L_{C}$ value of 8.08 which was caused by the relative cash flow rights share of the agreement equal to $12.38 \%$.

The analysis of the outliers for indirect agreements, the $L_{C}$ value of 5.83 for Olivetti is due to cash flow rights of the controller Bell of 17.15\%. 
From 2000 to 2002 there were no anomalous values.

For 2003 extraordinarily elevated $L_{C}$ values were found for Ducati (2.98) following 33.53\% cash flow rights held by the controlling company TPG Advisors; for Telecom Italia (8.16) due to $12.25 \%$ of cash flow rights held by Olimpia; in Unipol (2.59) owing to the share on cash flow rights of $38.68 \%$ by Holmo.

In 2004, Ducati were again present in the outliers with a $L_{C}$ equal to 2.98, Telecom Italia with 9.17 and Unipol with a $L_{C}$ equal to 2.9 .

In 2005, extraordinary $L_{C}$ values for Ducati with 2.86, Telecom Italia with 8.06 and Unipol with 3.08.

As well as $L_{C}$ values observed for Telecom Italia (8.05) and Unipol (3.18), in 2006 the highest values are observed in Aeroporto di Venezia with a $L_{C}$ value of 2.57 which is attributable to the share on cash flow rights of Marco Polo Holding at $38.98 \%$, and in Impregilo with a leverage of 3.36 due to the $29.74 \%$ share on cash flow rights held by Igli.

Among the outliers in 2007, Impregilo is still present with a leverage of 3.49; Telecom Italia with 6.15; Unipol with 3.18 and Interpump with 4.7 imputable to the share of $22.23 \%$ on cash flow rights held by IPG Holding.

In order to confirm as to whether the intensity of separation between ownership and control is tied to capitalisation, first of all an analysis by class was performed (see Table 10). More in particular, considering the threshold identified for the listing in the Blue Chip segment ( $€ 800$ million between 1999 and 2005 and $€ 1$ billion from 2005 onwards), the estimated leverage for the large cap. and the small medium cap. categories. From the comparison it emerges that the mean and median values of the large cap. category are always superior to those found in the small medium cap. with the exception of a few cases.

Table 10

Levers of Shareholder Agreements in Large and Small-Medium Companies

\begin{tabular}{|c|c|c|c|c|c|}
\hline \multirow{3}{*}{ Year } & \multicolumn{5}{|c|}{ Shareholder agreements } \\
\hline & & \multicolumn{2}{|c|}{$L_{C}$ of large cap. } & \multicolumn{2}{|c|}{$L_{C}$ of small-medium cap } \\
\hline & & Direct & Indirect & Direct & Indirect \\
\hline \multirow{2}{*}{1999} & Average & 2.17 & 3.07 & 1.88 & 2.06 \\
\hline & Median & 1.84 & 2.60 & 1.95 & 2.08 \\
\hline \multirow{2}{*}{2000} & Average & 2.23 & 2.60 & 2.04 & 2.22 \\
\hline & Median & 1.92 & 2.88 & 1.84 & 2.24 \\
\hline \multirow{2}{*}{2001} & Average & 2.12 & 2.77 & 1.89 & 2.21 \\
\hline & Median & 1.85 & 2.79 & 1.79 & 1.96 \\
\hline \multirow{2}{*}{2002} & Average & 2.57 & 2.34 & 1.88 & 1.89 \\
\hline & Median & 1.84 & 1.77 & 1.80 & 1.89 \\
\hline \multirow{2}{*}{2003} & Average & 2.67 & 2.90 & 2.00 & 1.76 \\
\hline & Median & 2.05 & 1.71 & 1.83 & 1.76 \\
\hline \multirow{2}{*}{2004} & Average & 2.41 & 3.83 & 2.08 & 1.71 \\
\hline & Median & 2.08 & 2.28 & 1.90 & 1.62 \\
\hline \multirow{2}{*}{2005} & Average & 2.30 & 3.62 & 1.94 & 1.73 \\
\hline & Median & 1.97 & 2.50 & 1.87 & 1.67 \\
\hline \multirow{2}{*}{2006} & Average & 2.48 & 3.09 & 2.18 & 1.74 \\
\hline & Median & 2.15 & 1.92 & 1.90 & 1.73 \\
\hline \multirow{2}{*}{2007} & Average & 2.54 & 2.69 & 2.02 & 1.90 \\
\hline & Median & 1.91 & 1.85 & 1.90 & 1.76 \\
\hline
\end{tabular}

Note. The table shows the mean and the median values of control lever and voting rights lever for companies subject to shareholder agreements (direct and indirect) with large and small-medium capitalization.

This is only partially confirmed by the results of the regression analysis between the capitalisation and the $L_{C}$ 
(see Table 11). The regression points out a positive linear relationship on the normalised variables, even with a contained $R^{2}$ value, probably due to the fact that the intensity of the $L_{C}$ also depends upon other variables beyond the size of the company. The capitalisation variable is not statistically significant only for the years of 2000 and 2007.

Table 11

Direct Agreements: Relationship Between Capitalization and $L_{C}$

\begin{tabular}{lcccccccccc}
\hline \multicolumn{10}{c}{$L c$} \\
\hline & 1999 & 2000 & 2001 & 2002 & 2003 & 2004 & 2005 & 2006 & 2007 \\
\hline Constant $^{*}$ & 0.349 & 0.456 & 0.231 & 0.319 & 0.270 & 0.334 & 0.251 & 0.328 & 0.455 \\
Cap $^{*}$ & 0.015 & $0.016^{* *}$ & 0.099 & 0.034 & 0.058 & 0.045 & 0.042 & 0.022 & $0.01^{* * *}$ \\
$R^{2}$ & 0.150 & 0.028 & 0.125 & 0.231 & 0.289 & 0.248 & 0.256 & 0.143 & 0.011 & 33 \\
Observations & 29 & 33 & 31 & 31 & 29 & 28 & 29 & 33 & 34 \\
\hline
\end{tabular}

Notes. ${ }^{*}$ Significant at $5 \% ;{ }^{* * *} P$-value is equal to $0.356 ;{ }^{* * *} P$-value is equal to 0.564 . The table shows the results of regression analysis, where the response variable is the control lever of companies subject to a direct agreements and the predictor variable is the companies capitalizations.

On the other hand, the relationship between $L_{C}$ and capitalisation for indirect agreements does not produce any statistical significance. In this case, the result could be influenced by the reduced amount of companies on which the regression analysis was performed.

\section{The Pyramidal Model}

In countries such as Italy the pyramid model has experienced a wide dispersion so much so as to become an out-and-out peculiarity of our system.

The pyramid structure is a particular configuration of corporate groups whereby the leader controls many listed companies, each of which in turn control other companies and so on. In this sense, it can be agreed that in pyramid structures different companies are bound by a common objective and even if each company is still individually liable to third parties, especially with regards to duties based on activities carried out, they are still all projected towards the same goal. Thus, the model that emerges constitutes the group, made up of different companies with diverse legal liability that are subject to the controlling economic entity, considering that the economic results of specific firms are relevant only with reference to the group as a whole (Airoldi, Brunetti, \& Coda, 1994). Generally speaking, the group risks taking on different forms due to the legal nature of the controlling company and the existing relationships between individual companies that participate in the group.

In particular, the meaning of control imposed at the base of this study coincides with that prevalent in doctrine by the controlling company, where control is inseparably linked to the possession of a quantity of shares that allows the conditioning of the decisional assemblies of the companies that constitute the group.

That includes those pertaining to the appointment of components within the board, in order to guarantee the consistency of single company decisions to the managerial directives put in place by the controlling company. Therefore the particular condition for which a company could be classed as controlled when under the dominant influence of another company due to contractual obligations that not relevant to its structure is not taken into consideration, to avoid the shifting of the analysis towards control conditions different from the tout court property.

In particular, for Italy, the number of pyramidal groups progressively diminished considerably from 29 in 
1999 to 19 in 2007 (see Table 12). Consequently, the incidence decreased as well, even if less in number than in capitalization, respectively decreasing from $33.33 \%$ to $14.24 \%$ and $69.83 \%$ to $38.88 \%$.

Table 12

Pyramidal Groups

\begin{tabular}{lllll}
\hline \multirow{2}{*}{ Year } & No. & Companies & \multicolumn{2}{c}{ Incidence (\%) } \\
\cline { 4 - 5 } & & & Stock market companies & Market cap. \\
2099 & 29 & 90 & 33.33 & 69.83 \\
2001 & 26 & 80 & 26.94 & 69.48 \\
2002 & 22 & 65 & 22.11 & 68.12 \\
2003 & 22 & 65 & 22.03 & 67.90 \\
2004 & 19 & 52 & 18.64 & 56.77 \\
2005 & 17 & 47 & 16.91 & 47.21 \\
2006 & 18 & 49 & 17.38 & 44.76 \\
2007 & 19 & 50 & 16.08 & 44.69 \\
Mean & 19 & 49 & 14.24 & 38.88 \\
\hline
\end{tabular}

Note. The table shows the number of Italian pyramidal groups, the number of companies belonging to a pyramidal group and their incidence on the total number of Italian listed companies and on market capitalization.

Table 13

Pyramidal Groups: The Incidence of Large and Small-Medium Companies

\begin{tabular}{|c|c|c|c|c|c|c|c|c|c|c|c|c|c|c|c|c|c|c|}
\hline \multirow{4}{*}{ Year } & \multicolumn{5}{|c|}{ Market } & \multicolumn{13}{|c|}{ Pyramidal groups } \\
\hline & \multirow{3}{*}{ Total } & & & & & \multirow{3}{*}{$\begin{array}{l}\text { Total companies } \\
\text { in pyramid }\end{array}$} & \multicolumn{6}{|c|}{$1^{\circ}$ Level } & \multicolumn{6}{|c|}{$2^{\circ}$ Level } \\
\hline & & \multicolumn{2}{|c|}{ Large cap. } & \multicolumn{2}{|c|}{ Small-medium cap. } & & \multicolumn{2}{|c|}{ Total of level } & \multicolumn{2}{|c|}{ Large cap. } & \multicolumn{2}{|c|}{$\begin{array}{l}\text { Small-medium } \\
\text { cap. }\end{array}$} & \multicolumn{2}{|c|}{ Total of level } & \multicolumn{2}{|c|}{ Large cap. } & \multicolumn{2}{|c|}{$\begin{array}{c}\text { Small-medium } \\
\text { cap. }\end{array}$} \\
\hline & & No. & Incidence & No. & Incidence & & No. & Incidence & No. & Incidence & No. & Incidence & No. & Incidence & No. & Incidence & No. & Incidence \\
\hline 1999 & 270 & 85 & $31.48 \%$ & 185 & $68.52 \%$ & 90 & 30 & $33.33 \%$ & 16 & $53.33 \%$ & 14 & $46.67 \%$ & 41 & $45.56 \%$ & 18 & $43.90 \%$ & 23 & $56.10 \%$ \\
\hline 2000 & 297 & 97 & $32.66 \%$ & 200 & $67.34 \%$ & 80 & 28 & $35.00 \%$ & 19 & $67.86 \%$ & 9 & $32.14 \%$ & 37 & $46.25 \%$ & 20 & $54.05 \%$ & 17 & $45.95 \%$ \\
\hline 2001 & 294 & 91 & $30.95 \%$ & 203 & $69.05 \%$ & 65 & 25 & $38.46 \%$ & 12 & $48.00 \%$ & 13 & $52.00 \%$ & 27 & $41.54 \%$ & 13 & $48.15 \%$ & 14 & $51.85 \%$ \\
\hline 2002 & 295 & 81 & $27.46 \%$ & 214 & $72.54 \%$ & 65 & 24 & $36.92 \%$ & 10 & $41.67 \%$ & 14 & $58.33 \%$ & 30 & $46.15 \%$ & 14 & $46.67 \%$ & 16 & $53.33 \%$ \\
\hline 2003 & 279 & 77 & $27.60 \%$ & 202 & $72.40 \%$ & 52 & 20 & $38.46 \%$ & 10 & $50.00 \%$ & 10 & $50.00 \%$ & 24 & $46.15 \%$ & 11 & $45.83 \%$ & 13 & $54,17 \%$ \\
\hline 2004 & 278 & 82 & $29.50 \%$ & 196 & $70.50 \%$ & 47 & 18 & $38.30 \%$ & 10 & $55.56 \%$ & 8 & $44.44 \%$ & 21 & $44.68 \%$ & 11 & $52.38 \%$ & 10 & $47.62 \%$ \\
\hline 2005 & 282 & 89 & $31.56 \%$ & 193 & $68.44 \%$ & 49 & 19 & $38.78 \%$ & 10 & $52.63 \%$ & 9 & $47.37 \%$ & 22 & $44.90 \%$ & 12 & $54.55 \%$ & 10 & $45.45 \%$ \\
\hline 2006 & 311 & 84 & $27.01 \%$ & 227 & $72.99 \%$ & 50 & 19 & $38.00 \%$ & 10 & $52.63 \%$ & 9 & $47.37 \%$ & 22 & $44.00 \%$ & 11 & $50.00 \%$ & 11 & $50.00 \%$ \\
\hline 2007 & 344 & 87 & $25.29 \%$ & 257 & $74.71 \%$ & 49 & 20 & $40.82 \%$ & 9 & $45.00 \%$ & 11 & $55.00 \%$ & 22 & $44.90 \%$ & 8 & $36.36 \%$ & 14 & $63.64 \%$ \\
\hline \multirow[t]{4}{*}{ Mean } & 294 & 86 & $29.28 \%$ & 209 & $70.72 \%$ & 61 & 23 & $37,56 \%$ & 12 & $51.85 \%$ & 11 & $48.15 \%$ & 27 & $44.90 \%$ & 13 & $47.99 \%$ & 14 & $52.01 \%$ \\
\hline & \multicolumn{6}{|c|}{$3^{\circ}$ Level } & \multicolumn{6}{|c|}{$4^{\circ}$ Level } & \multicolumn{6}{|c|}{$5^{\circ}$ Level } \\
\hline & \multicolumn{2}{|c|}{ Total of level } & \multicolumn{2}{|c|}{ Large cap. } & \multicolumn{2}{|c|}{$\begin{array}{l}\text { Small-medium } \\
\text { cap. }\end{array}$} & \multicolumn{2}{|c|}{ Total of level } & \multicolumn{2}{|c|}{ Large cap. } & \multicolumn{2}{|c|}{$\begin{array}{l}\text { Small-medium } \\
\text { cap. } \\
\end{array}$} & \multicolumn{2}{|c|}{ Total of level } & & arge cap. & Sma & $\begin{array}{l}\text { ll-medium } \\
\text { cap. }\end{array}$ \\
\hline & No. & Incidence & No. & Incidence & No. & Incidence & No. & Incidence & No. & Incidence & No. & Incidence & No. & Incidence & No. & Incidence & No. & Incidence \\
\hline 1999 & 14 & $15.56 \%$ & 8 & $57.14 \%$ & 6 & $42.86 \%$ & 5 & $5.56 \%$ & 4 & $80.00 \%$ & 1 & $20.00 \%$ & 0 & - & - & - & - & - \\
\hline 2000 & 14 & $17.50 \%$ & 8 & $57.14 \%$ & 6 & $42.86 \%$ & 1 & $1.25 \%$ & 0 & $0.00 \%$ & 1 & $100.00 \%$ & 0 & - & - & - & - & - \\
\hline 2001 & 8 & $12.31 \%$ & 5 & $62.50 \%$ & 3 & $37.50 \%$ & 2 & $3.08 \%$ & 2 & $100.00 \%$ & - & - & 3 & $4.62 \%$ & 1 & $33.33 \%$ & 2 & $66.67 \%$ \\
\hline 2002 & 8 & $12.31 \%$ & 5 & $62.50 \%$ & 3 & $37.50 \%$ & 1 & $1.54 \%$ & 1 & $100.00 \%$ & - & - & 2 & $3.08 \%$ & - & - & 2 & $100.00 \%$ \\
\hline 2003 & 8 & $15.38 \%$ & 7 & $87.50 \%$ & 1 & $12.50 \%$ & - & - & - & - & - & - & - & - & - & - & - & - \\
\hline 2004 & 8 & $17.02 \%$ & 6 & $75.00 \%$ & 2 & $25.00 \%$ & - & - & - & - & - & - & - & - & - & - & - & - \\
\hline 2005 & 8 & $16.33 \%$ & 5 & $62.50 \%$ & 3 & $37.50 \%$ & - & - & - & - & - & - & - & - & - & - & - & - \\
\hline 2006 & 9 & $18.00 \%$ & 5 & $55.56 \%$ & 4 & $44.44 \%$ & - & - & - & - & - & - & - & - & - & - & - & - \\
\hline 2007 & 7 & $14.29 \%$ & 3 & $42.86 \%$ & 4 & $57.14 \%$ & - & - & - & - & - & - & - & - & - & - & - & - \\
\hline Mean & 9 & $15.41 \%$ & 6 & $62.52 \%$ & 4 & $37.48 \%$ & 2 & $2.86 \%$ & 2 & $70.00 \%$ & 1 & $60.00 \%$ & 1 & $3.85 \%$ & 1 & $33.33 \%$ & 2 & $83.33 \%$ \\
\hline
\end{tabular}

Note. The table reports the incidence of the large and small-medium capitalization companies for the market companies and the companies belonging to a pyramidal group on the total number respectively of the market, the companies belonging to a pyramidal group and the companies of each pyramidal level. 
The author finds that the dimension of the company that highlights a strong influence of companies with greater capitalisation for the entire period. In fact, the weight on the capitalisation of companies that are part of a pyramid group is considerably higher than the incidence on the number of companies for each year. Analysing the capitalisations, the relative frequency of larger companies part of the pyramid group for each level of the chain results superior to the relative frequency of larger companies of the market in its entirety in all of the years that have been studied (see Table 13).

Starting once again with the assumption that the acquisition of control within larger companies requires a superior financial commitment, it can be assumed that pyramid models represent a solution that is adopted most of all by shareholders in companies with higher capitalisation to reach control whilst limiting relative investment.

With reference to integrated ownership from the comparison between mean and median in the first level of the chain a little prominent skew is noted (see Table 14). In particular the skew is positive from 2001 to 2004 and in 2007 owing to the presence of considerably high values ${ }^{28}$ and is negative for the remaining years because of the presence of extremely contained values ${ }^{29}$. In the second level the differences between mean and median are greatly marked with a positive skew for the entire period of the study given the presence of particularly high values $^{30}$. In the third and successive levels the skew remains positive and is resized in the entire period following particularly high values ${ }^{31}$, with the exception of 2005 and 2006 where the values were particularly low ${ }^{32}$. With regards to the group ownership the differences between mean and median become particularly prominent from the second level onwards. The skew is positive for the entire period due to the presence of very high values in the first level ${ }^{33}$. However the second level demonstrates a positive skew between 1999 and $2002^{34}$ and a negative skew between 2003 and $2007^{35}$. In successive levels a positive skew is found for 1999, 2001, 2002, 2003 and 2004 for the presence of higher values ${ }^{36}$ and a negative skew in 2000, 2005, 2006 and 2007 owing to the level of extraordinary low levels.

\footnotetext{
28 The highest shares of integrated ownership are held by Italenergia (88.83\%) and Caltagirone family (84.26\%) in 2001; Caltagirone family in Caltagirone (86.8\%) in 2002, in 2003 and in 2004; Caltagirone family (87.64\%) and Cabassi family in Bastogi (71.35\%) in 2007.

29 The lowest shares of integrated ownership are held by Bell in Olivetti in 1999 (17.10\%) and in 2000 (25.21\%), Pesenti family in Italmobiliare (27.6\%) and 2006 (27.57\%).

${ }^{30}$ The highest shares of integrated ownership are held by Zucchi in Bassetti (65.44\%) in 1999 and 2005, Montedison in Edison (88.81\%) in 2002, Caltagirone in Vianini Lavori (at around 60\%) from 2002 to 2007.

31 The highest shares of integrated ownership are held in the Intesa group, by Banca Commerciale (29.27\%) and Banca di Legnano (23.22\%) in 1999 and 2000; by Pirelli in Olivetti (at around 14\%) in 2001 and 2002; in the Cofide group by Sogefi (10\%) in 2003 and 2004; by Atlantia in Autostrade Meridionali (35.39\%) and by Ifil in Juventus (23.27\%) in 2007.

32 The lowest shares of integrated ownership are held by Telecom Italia in Telecom Italia Media (2.12\%), by Generali in Alleanza (4.23\%) in 2005; by Telecom Italia in Telecom Italia Media (3.03\%), and by Generali in Alleanza (4,33\%) in 2006.

33 In the study period, the totalitarian share of ordinary capital held by Giovanni Agnelli in Ifi.

34 The highest shares of group ownership are held by Finmeccanica in Fiar (86.6\%), by Zucchi in Bassetti (85.02\%) in 1999; by Zucchi (85.02\%) in Bassetti, by Ras in Allianz (96.52\%) in 2000; by Buzzi in Unimed (76.88\%) and by Istituto San Paolo in Banca Fideuram (74.82\%) in 2001; by Istituto San Paolo in Banca Fideuram (73.58\%) and in Banca Popolare Adriatica (70.87\%) in 2002.

35 During 2003-2007 the lowest shares of group ownership are held by Mediobanca (3.63\%) in Generali (in 2007 these shares rose to $15.67 \%$ ).

${ }^{36}$ In 1999 the highest shares are held in Banca Commerciale and in Banco di Chiavari (69.75\%); by Fiat in Toro, (65.15\%), and in Magneti Marelli (65.78\%); by Cir in Sogefi (43\%) and by La Fondiaria in Milano Assicurazioni (38\%) in 2001, 2002, 2003 and 2004.
} 
Table 14

Ownership in Pyramidal Groups

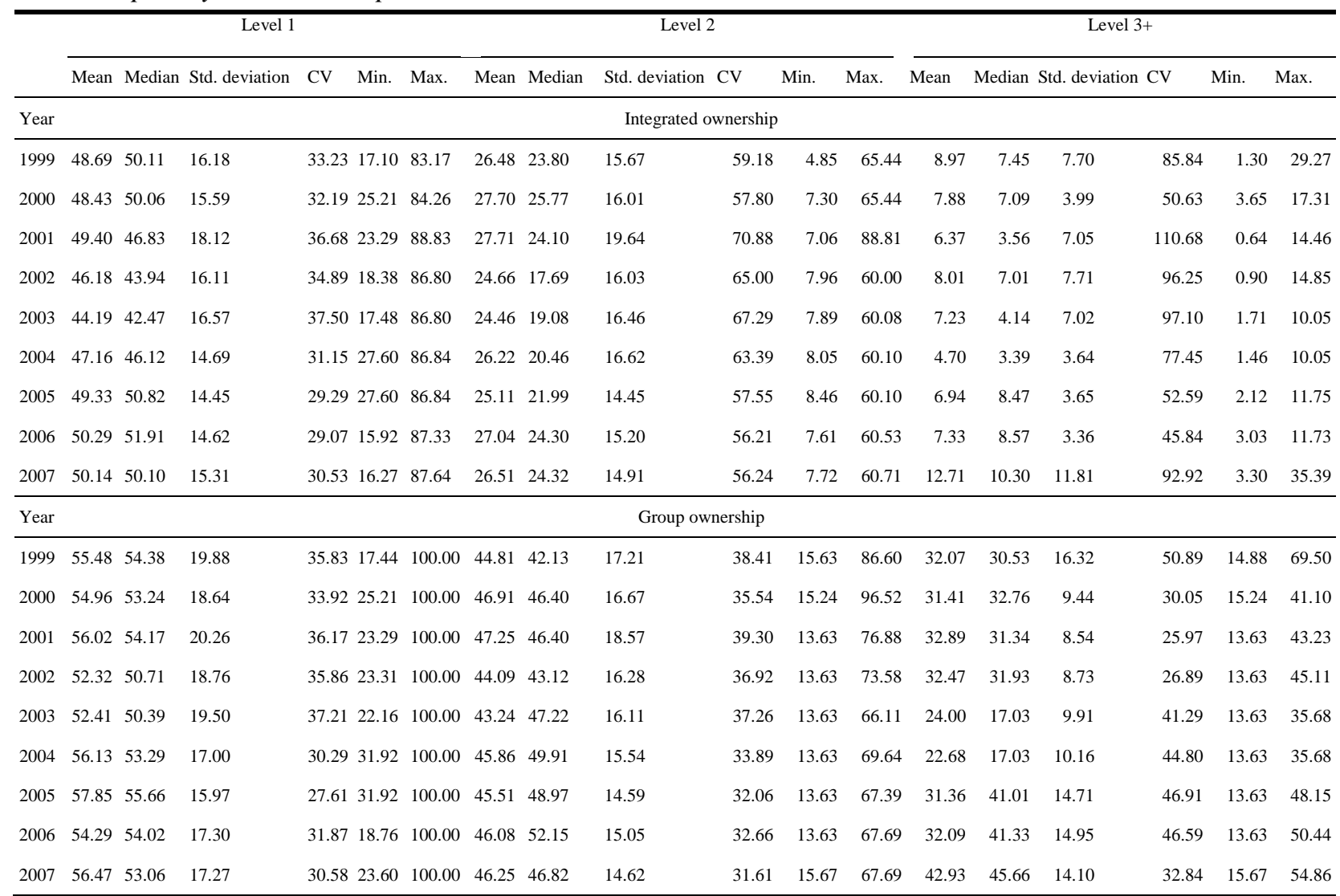

Note. The table shows the mean, the median, the standard deviation, the coefficient of variation, the minimum and the maximum of the cash flow rights and voting rights for all levels of the pyramidal chain held by the largest shareholder.

Within the levels of the pyramid chain after the first, the analysis also shows a prominent dispersion, both for the integrated ownership and for the group ownership given the high value of the standard deviation and of the coefficient of variation. The dispersal is therefore demonstrated by the range which remains consistent during the entire study period.

Given the difference between the two position index, the median can be considered more suitable to summarise the phenomenon within the different years.

In the analyzed period the median shows a substantial stability within the first two levels, whose values of integrated ownership and group ownership in the beginning of the period are not very distant from those at the end of the period. On the contrary, there is greater instability in the median values within the third level, both for integrated ownership and group ownership. This stability is explained by a lower number of companies belonging to the third level and by the operations of shortening the chain of control occurring in the main control groups that were affected, obviously, primarily the lower level of the chain.

All these show that the strengthening of the minority shareholders protection did not influence the integrated ownership and the group ownership control within the various levels and so did not substantially change the intensity of separation that were taken by the controlling shareholder in the pyramid, despite having led to the 
simplification of the chains, as shown, the reduction of the companies that were involved in the phenomenon. In other words, in the period 1999-2007 the groups affected by the simplifications of the control chain mostly represented by a shift of value (in terms of capitalization) from the bottom to the top and essentially with no effect on the proportionality between cash flow rights and voting rights. Moreover this is confirmed by the $L_{V R}$ and the $L_{C}$ whose median values do not show significant changes over the years.

Where the higher values of the leverage are compared with the leverage of the dual class system and shareholder agreements, the separation between ownership and control being more intense in the pyramid model is confirmed, above all because of the amplification generated by a cascade structure.

As it is the case with the other two CEMs, the differences between means and medians of the $L_{C}$ and of the $L_{V R}$ demonstrate a strong dispersal and a skew, the origin of which can be attributed to the following values that appear from the analysis of the outliers (see Table 15).

Table 15

Levers of Pyramidal Groups

\begin{tabular}{|c|c|c|c|c|c|c|c|c|c|c|c|c|}
\hline \multirow[b]{2}{*}{ Year } & \multicolumn{6}{|c|}{$L_{C}$} & \multicolumn{6}{|c|}{$L_{V R}$} \\
\hline & Mean & Median & $\begin{array}{l}\text { Std. } \\
\text { deviation }\end{array}$ & $\mathrm{CV}$ & Min. & Max. & Mean & Median & $\begin{array}{l}\text { Std. } \\
\text { deviation }\end{array}$ & $\mathrm{CV}$ & Min. & Max. \\
\hline 1999 & 10.01 & 4.97 & 13.33 & 133.17 & 1.53 & 80.14 & 2.89 & 2.14 & 2.42 & 83.74 & 1.00 & 11.92 \\
\hline 2000 & 7.08 & 4.19 & 6.60 & 93.22 & 1.53 & 80.14 & 2.50 & 1.87 & 1.52 & 60.80 & 1.00 & 48.82 \\
\hline 2001 & 17.84 & 4.13 & 36.98 & 207.29 & 1.00 & 155.76 & 5.81 & 1.91 & 10.76 & 185.20 & 1.00 & 48.82 \\
\hline 2002 & 12.34 & 5.65 & 24.39 & 197.65 & 1.67 & 110.98 & 4.00 & 1.98 & 6.85 & 171.25 & 1.00 & 31.21 \\
\hline 2003 & 10.20 & 5.14 & 14.32 & 140.46 & 1.66 & 68.62 & 2.87 & 2.22 & 2.88 & 100.48 & 1.06 & 14.24 \\
\hline 2004 & 11.30 & 5.79 & 23.64 & 209.21 & 1.66 & 109.92 & 3.21 & 2.27 & 3.75 & 116.77 & 1.11 & 18.72 \\
\hline 2005 & 8.00 & 4.82 & 9.33 & 116.67 & 1.66 & 47.25 & 2.71 & 2.10 & 1.65 & 60.96 & 1.11 & 8.05 \\
\hline 2006 & 7.40 & 4.38 & 7.78 & 105.20 & 1.52 & 32.97 & 2.56 & 1.96 & 1.40 & 54.70 & 1.00 & 5.94 \\
\hline 2007 & 6.80 & 4.12 & 6.94 & 102.06 & 1.47 & 30.32 & 2.80 & 1.84 & 3.02 & 107.77 & 1.00 & 16.63 \\
\hline Mean & 10.11 & 4.80 & 15.92 & 144.99 & 1.52 & 79.57 & 3.26 & 2.03 & 3.81 & 104.63 & 1.03 & 22.71 \\
\hline
\end{tabular}

Note. The table shows the values of the mean, the median, the standard deviation, the coefficient of variation, the minimum and the maximum for the control lever and the voting rights lever.

In 1999 extraordinarily high values are found in the Olivetti group of which the $L_{C}$ on Tim is 42.39, attributable to the particularly contained value of the integrated ownership of 2.36 and a $L_{V R}$ equal to 7.39 caused by the group ownership of $60.14 \%$ and by the presence of shares with limited voting rights at $19.08 \%$ of stock. The $L_{C}$ of Sirti is 57.88 compared to an integrated ownership of $1.73 \%$, while the $L_{V R}$ is equal to 10.09 attributable to a group ownership of $49.1 \%$ and shares with limited voting rights at $27.4 \%$ of capital stock. In the Mediobanca group, the $L_{C}$ for Unione Immobiliare is 76.73 for an integrated ownership of $1.3 \%$, while the $L_{V R}$ is equal to 11.41 for a group ownership of $14.88 \%$. In the Agnelli group there are particularly high $L_{C}$ levels for Toro equal to 31.61 attributable to the integrated ownership of $3.16 \%$.

The outliers for 2000 are found in the Mediobanca group, for the $L_{C}$ on Alleanza at 27.42 caused by an integrated ownership equal to $3.65 \%$ and in the Agnelli group, for a $L_{C}$ on Toro at 26.08 and a $L_{V R}$ equal to 8.01.

In 2001, as well as the Mediobanca group with a $L_{C}$ on Alleanza of 30.89, dysfunctional values are found also in the Premafin group for the $L_{C}$ in Milano Assicurazioni at 39.03 following an integrated ownership of $2.56 \%$, and for the $L_{V R}$ on Milano Assicurazioni equal to 14.79 attributable to a group property of $38 \%$ and at the 
presence of shares with limited voting rights equal to $8.31 \%$ of capital stock. The Pirelli group also presents extraordinarily high values in Tim for a $L_{C}$ of 128.32 caused by an integrated ownership of $0.88 \%$ and by a $L_{V R}$ of 35.63 against a group ownership of $28 \%$ and of shares with limited voting rights at $1.54 \%$ of stock; in Immsi for a $L_{C}$ of 113.99 caused by an integrated ownership of $0.78 \%$ and for a $L_{V R}$ of 31.65 against a group ownership of $28 \%$; in Seat for a $L_{C}$ of 155.76 due to the integrated ownership of $0.64 \%$ and for a $L_{V R}$ of 48.82 attributable to the group ownership of $31 \%$.

In 2002 the outliers are again represented by particularly high levels within the Pirelli group, for a $L_{C}$ in Tim equal to 110.98 and a $L_{V R}$ in Tim of 30.82; for the $L_{C}$ in Seat of 104.49 and a $L_{V R}$ in Seat equal to 31.21; and in the Mediobanca group for the $L_{C}$ in Alleanza of 26.57 .

Anomalous values are shown in 2003 for the Pirelli group for Tim, with a $L_{C}$ of 58.63 and $L_{V R}$ of 9.98, and for Telecom Italia Media, with $L_{C}$ of 52.72 and $L_{V R}$ equal to 8.98; in the Mediobanca group for Alleanza, with $L_{C}$ at 24.16 and in the Premafin group for Milano Assicurazioni with a $L_{V R}$ equal to 7.93.

In 2004 the outliers included the Pirelli group for the $L_{C}$ and the $L_{V R}$ on Tim of 68.62 and 11.62 respectively, for the $L_{C}$ and the $L_{V R}$ on Telecom Italia Media of 61.7 and 10.51 respectively, and the Mediobanca group for the $L_{C}$ on Alleanza equal to 24.16 .

The outliers for 2005 were also Mediobanca group for the $L_{C}$ on Alleanza of 23.08 and in the Pirelli group for the $L_{C}$ and the $L_{V R}$ on Telecom Italia Media of 47.25 and 8.05 respectively.

In 2006, extraordinarily high values were found in Mediobanca for a $L_{C}$ on Alleanza of 23.08 and in the Pirelli group for a $L_{C}$ and $L_{V R}$ on Telecom Italia Media of 32.97 and 5.94 respectively.

Finally in 2007, dysfunctional values are found in Mediobanca group for the $L_{C}$ on Alleanza of 25.78\%, and in the Premafin group for the $L_{C}$ and the $L_{V R}$ on Immobiliare Lombarda equal to 30.32 and 16.63 respectively.

Regarding the possible relationship between the intensity of the leverage and capitalisation of the company that the leverage is referred to, pyramid groups generate a leverage on the company at the base of the pyramid attributable to the company itself only in a minimal part, unlike the dual class system and shareholder agreements. The relationship depends on the controlling share on that company, but also mainly depends on the controlling shares associated at the different levels of the group, from the eventual shares with limited voting rights present in the companies within the group and lastly by the length of the pyramid. In this way for example, a higher leverage on the company at the base of the pyramid can be explained primarily in the intensity of the separation that the shareholder at the vertex of the group has reached in the different levels, of which the base company represents only certain part. Neither from the other side the relationship can be studied between leverage on the company at the base of the pyramid and capitalisation of the entire group as highlighted by the regression analysis carried out between $L_{V R}$ and group capitalisation that led to the exclusion of a relationship between these two volumes, not even considering the outlier values.

\section{Conclusions}

This article, which has attempted to demonstrate the existing differences between various CEMs has examined recurrence and the intensity of the main separation mechanisms between ownership and control for Italian companies in the period of 1999-2007 which is characterised by legal measures that have influenced the level of protection of shareholders. 
For the types of CEMs analysed in the investigation and represented by dual class systems, shareholder agreements and pyramid models, it has been demonstrated that the recurrence to CEMs is more widespread between companies with greater capitalisation.

In fact, there is no doubt that when the amount of financial investment associated to control reaches consistent levels due to the size of companies, then the different instruments available to improve the relationship between voting rights and capital investment become much more attractive to the controlling shareholder.

The study has also revealed that the three mechanisms are united by dispersal and skew of the observed data that leads to presume significantly differentiated behaviours by he company, some of which can be distinguished by aggravating the separation between voting rights and cash flow rights.

With the exception of these common elements, the three devices have highlighted very different characteristics and evolutionary dynamics.

For the dual class system, the study has revealed that the issue of shares with limited voting rights is conceived by the shareholder not in order to obtain control but rather to consolidate its position as controller. In other words, it has been ascertained that this method of separation between voting rights and cash flow rights is resorted to by shareholders who are already in control of the company, holding a share of ownership on average of around 50\%. Under the profile of evolutionary dynamics, dual class systems have recorded a progressive downturn in number and in capitalisation, yet only attributable in part to operations of conversion into one class.

It has been demonstrated that direct shareholder agreements are stipulated mainly with the aim of acquiring control, even if control is shared with other shareholders.

The most recurrent characteristic between the companies involved is the median of the controlling share of $50 \%$, which in itself compensates for the major shareholder's inability to exercise disjointed control from other shareholders owing to a median share of $19 \%$.

In the period studied controlling agreements have shown stability in terms of capitalisation and a growing progression in popularity, contrary to the other two separation devices and the origin of which is attributable to the superior versatility that marks these methods.

For pyramid models the empiric evidence has revealed a significant contraction during the study period that has progressively reduced the positive differential with respect to the other two CEMs in terms of companies involved. Mainly and above all within the primary pyramid groups this contraction was achieved with shortening operations and simplifications of the controlling chain. These findings demonstrate that the growth concerning the protection of shareholders due to regulatory changes has produced different effects on each of the three mechanisms, with greater intensity on the devices like the pyramids that consent to separate more efficiently ownership from control. The increased informative transparency derived from successive regulatory interventions has definitely resized the amount of pyramid groups and dual class companies, but not the existing disproportion between voting rights and cash flow rights which remains particularly high in each single company, contrarily for shareholder agreements whose recurrence and intensity has not been marked by normative variations.

Therefore the paper has shown stock levers that are constantly higher in pyramid groups due to the cascade structure that amplifies the separation between voting rights and cash flow rights, it has also shown essentially constant stock leverage in the period for dual class structures, direct agreements and pyramidal groups, 
demonstrating that the intensity of separation did not change during the years for the companies involved.

Basically, since 1999, the legislative changes have reduced the adoption of the CEMs and in particular both in the pyramids, and in the dual class structures among the Italian companies, while having no significant effect on how these companies separate the ownership from control.

\section{References}

Airoldi, G., Brunetti, G., \& Coda, V. (1994). Economia aziendale. Bologna: Il Mulino.

Almeida, H., \& Wolfezon, D. (2006). A theory of family business group and pyramidal ownership. Journal of Finance, 61, 2637-2680.

Bennedsen, M., \&. Wolfenzon, D. (2000). The balance of power in closely held corporations. Journal of Financial Economics, 58, 113-119.

Berle, A., \& Means, G. (1932). The modern corporation and private property. New York: MacMillan.

Bertrand, M., Mehta, P., \& Mullainathan, S. (2002). Ferreting out tunneling: An application to indian business groups. Quarterly Journal of Economics, 117, 121-148.

Bianchi, M., Bianco, M., \& Enriques, L. (2001). Pyramidal groups and the separation between ownership and control in Italy. In F. Barca, \& M. Becht (Eds.), The control of corporate Europe. Oxford University Press.

Bianco, M., \& Nicodano, G. (2006). Pyramidal groups and debt. European Economic Review, 50, 937-961.

Brealey, R. A.,. Myers, S. C., Allen, F., \& Sandri, S. (2007). Principi di Finanza Aziendale. Milan: McGraw-Hill.

Burkart, M., \& Lee, S. (2008). One share-one vote: The theory. Review of Finance, 12, 1-49.

Chemla, G., Habib, M. A., \& Ljungqvist, A. (2007). An analysis of shareholder agreements. Journal of the European Economic Association, 5, 93-121.

Claessens, S., Fan, J. P. H., \& Lang, L. H. P. (2006). The benefits and costs of group affiliation: Evidence from East Asia. Emerging Markets Review, 7, 1-26.

Demsetz, H., \& Lehn, K. (1985). The structure of corporate ownership: Causes and consequences. Journal of Political Economy, 93, 1155-1177.

Faccio, M., \& Lang, L. (2002). The ultimate owner of Western European corporations. Journal of Financial Economics, 65, 365-395.

Faccio, M., Lang, L., \& Young, L. (2001). Dividends and expropriation. American Economic Review, 91, 54-78.

Gangopadhyay, S., Lensink, R., \& Van Der Molen, R. (2003). Business groups, financing constraints and investment: The case of India. Journal of Development Studies, 40, 93-119.

Gianfrate, G. (2007). What do shareholders' coalitions really want? Evidence from Italian voting trusts. Corporate Governance: An International Review, 15, 122-132.

Gomes, A., \& Novaes, W. (2005). Sharing of control versus monitoring as corporate governance mechanisms. Working paper, University of Pennsylvania, Washington University in St. Louis.

Gopalan, R., Nanda, V., \& Seru, A. (2007). Affiliated firms and financial support: Evidence from Indian business groups. Journal of Financial Economics, 86, 759-795.

Grossman, S., \& Hart, O. (1988). One share-one vote and the market for corporate control. Journal of Financial Economics, 20, 175-202.

ISS Europe, ECGI, Shearman \& Sterling. (2007). Report on the proportionality principle in the European Union. External study commissioned by the European Commission, Final Report.

Intrisano, C. (n.d.). Proprietà e controllo: dual class, patti parasociali e gruppi piramidali. Un'analisi sulle società italiane quotate in borsa. Roma: Aracne Editrice.

Johnson, S., La Porta, R., Lopez-de.Silanes, F., \& Shleifer, A. (2000). Tunneling. American Economic Review, 90, 22-27.

Khanna, T., \& Palepu, K. (1997). Why focuses strategies may be wrong for emerging markets. Harward Business Review, 75, 41-49.

La Porta, R., Lopez-de-Silanes, F., \& Shleifer, A. (1999). Corporate ownership around the world. Journal of Finance, 54, $471-517$.

La Porta, R., Lopez-de-Silanes, F., Shleifer, A., \& Vishny, R. (1997). Legal determinants of external finance. Journal of Finance, 52, 1131-1150. 
La Porta, R., Lopez-de-Silanes, F., Shleifer, A., \& Vishny, R. (1998). Law and finance. Journal of Political Economy, 106, 1113-1155.

Laeven, L., \& Levine, R. (2008). Complex ownership structures and corporate valuations. Review of Financial Studies, 21, 579-604. Lamont, O. (1997). Cash flow and investment: Evidence from internal capital markets. Journal of Finance, 52, 57-82.

Piga, C. A. G. (2002). Debt and firms' relationship: the Italian evidence. Review of Industrial Organization, 20, $267-282$.

Riyanto, Y. E., \& Toolsema, L. A. (2008). Tunneling and propping: A justification for pyramidal ownership. Journal of Banking and Finance, 32, 2178-2187.

Shin, H. H., \& Stulz, R. M. (1998). Are internal capital markets efficient? Quarterly Journal of Economics, 113, 531-552.

Volpin, P. (2002). Governance with poor investor protection: evidence from top executive turnover in Italy. Journal of Financial Economics, 64, 61-90.

Zingales, L. (1994). The value of the voting right: A study of the Milan stock exchange experience. Review of Financial Studies, 7 , 125-148. 